\begin{abstract}
UNIVERSIDAD PERUANA DE CIENCIAS APLICADAS
FACULTAD DE INGENIERÍA

PROGRAMA ACADÉMICO DE INGENIERÍA DE SISTEMAS DE

INFORMACIÓN
\end{abstract}

Modelo de madurez de protección de datos personales para el sector microfinanciero peruano

\title{
TESIS
}

Para optar el título profesional de Ingeniero de Sistemas de Información

\author{
AUTORES \\ Calle Gamero, Luis Alfredo (0000-0002-8859-5680) \\ García Herrera, Arturo Augusto (0000-0002-2214-9741) \\ ASESOR DE TESIS \\ Velásquez Núñez, Ángel Augusto (0000-0003-4702-2576)
}

Lima, Enero 2019 


\section{Resumen Ejecutivo}

El sector micro financiero pese a los esfuerzos que realiza no cumple satisfactoriamente la ley de protección de datos personales y las regulaciones propias de su ámbito de negocio.

El presente trabajo propone un modelo de madurez de protección de datos personales el cual está basado en recomendaciones de estándares internacionales de privacidad y seguridad de información que permita conocer si la organización cumple de manera satisfactoria la ley de protección de datos personales.

La validación del modelo consta de dos partes, la primera por juicio de expertos en el campo del sector micro financiero, de protección de datos personales y de la Superintendencia Nacional de Banca y Seguros. Posteriormente se realiza una evaluación de diagnóstico a cinco empresas del sector micro financiero y se analizan los resultados.

Palabras claves: modelo de madurez, protección de datos personales, micro financieras. 


\begin{abstract}
The micro financial sector despite the efforts made, does not satisfactorily comply with the law of personal data protection and the regulations of its business scope.

The present work proposes a mature model of personal data protection which is based on recommendations of international standards of privacy and information security that allows knowing if the organization is fulfilling in a satisfactory way the law of personal data protection.

The validation of the model is divided in two parts, the first by expert judgment in the field of the microfinance sector, the personal data protection and the National Superintendence of Banking and Insurance. Subsequently, a diagnostic evaluation is made to five companies in the microfinance sector and the results are analyzed.
\end{abstract}

Keywords: Maturity model, personal data protection, microfinance. 


\section{Tabla de Contenido}

Introducción $\quad 10$

Capítulo 1. Definición del Proyecto 12

$\begin{array}{ll}\text { Objeto de Estudio } & 13\end{array}$

Dominio del problema 13

Planteamiento del problema $\quad 14$

$\begin{array}{ll}\text { Objetivos del Proyecto } & 14\end{array}$

$\begin{array}{ll}\text { Objetivo general } & 14\end{array}$

Objetivos específicos $\quad 15$

Fuente: Elaboración propia $\quad 15$

Indicadores de éxito $\quad 15$

Fuente: Elaboración propia $\quad 15$

$\begin{array}{ll}\text { Alcance del proyecto } & 15\end{array}$

Capítulo 2: Student Outcomes $\quad 17$

$\begin{array}{ll}\text { Competencias específicas } & 18\end{array}$

$\begin{array}{ll}\text { Student Outcome A } & 18\end{array}$

$\begin{array}{ll}\text { ISO/IEC 27002 - CMMI: } & 18\end{array}$

$\begin{array}{ll}\text { Student Outcome B } & 19\end{array}$

Propuesta de Modelo 19

$\begin{array}{ll}\text { Student Outcome C } & 19\end{array}$

$\begin{array}{ll}\text { Propuesta de Modelo } & 19\end{array}$

$\begin{array}{ll}\text { Student Outcome D } & 20\end{array}$

Representantes de Micro financieras $\quad 20$

$\begin{array}{ll}\text { Student Outcome E } & 20\end{array}$

Análisis de situación actual 20

$\begin{array}{ll}\text { Student Outcome F } & 21\end{array}$

$\begin{array}{ll}\text { Referencias bibliográficas } & 21\end{array}$

$\begin{array}{ll}\text { Student Outcome G } & 21\end{array}$

Reuniones con comité, profesor cliente y profesor gerente 21

Student Outcome H 21 
Beneficios del modelo

$\begin{array}{ll}\text { Student Outcome I } & 22\end{array}$

Estándares y normas regulatorias $\quad 22$

Student Outcome J 22

Impacto del modelo propuesto $\quad 22$

$\begin{array}{ll}\text { Student Outcome K } & 22\end{array}$

$\begin{array}{ll}\text { Estándares } & 23\end{array}$

$\begin{array}{ll}\text { Competencias Generales } & 23\end{array}$

Comunicación escrita 23

Aplicación 23

Comunicación oral 23

Aplicación $\quad 23$

$\begin{array}{ll}\text { Ciudadanía } & 24\end{array}$

$\begin{array}{ll}\text { Aplicación } & 24\end{array}$

Pensamiento innovador $\quad 24$

$\begin{array}{ll}\text { Aplicación } & 24\end{array}$

Pensamiento crítico $\quad 24$

Aplicación $\quad 24$

Razonamiento cuantitativo $\quad 25$

$\begin{array}{ll}\text { Aplicación } & 25\end{array}$

Manejo de la información $\quad 25$

Aplicación $\quad 25$

Capítulo 3. Marco Teórico 26

Circular g-140 - $2009 \quad 27$

ISO $17944+27$

ISO $27002+27$

$\begin{array}{ll}\text { ISO } 29100 & 27\end{array}$

$\begin{array}{ll}\text { Ley de protección de datos personales } & 27\end{array}$

$\begin{array}{ll}\text { Modelo de madurez } & 28\end{array}$

$\begin{array}{ll}\text { PYME } & 28\end{array}$

Capítulo 4: Estado del Arte $\quad 29$

Selección de documentos $\quad 30$

Revisión de la literatura $\quad 34$

Modelos de madurez de seguridad de información 35 
Modelo de madurez para el gobierno de información

Modelo de madurez de seguridad de información financiera 36

Modelo de madurez de seguridad de información para medianas empresas 38

Modelo de madurez de seguridad de información aplicable a todas las organizaciones 40

Capítulo 5: Desarrollo del Proyecto $\quad 41$

Investigación y análisis de trabajos similares $\quad 42$

Temas de investigación $\quad 42$

Ciberseguridad 42

Protección de datos $\quad 42$

Sector financiero y micro financiero $\quad 42$

Seguridad de información $\quad 42$

Modelos de madurez relacionados a seguridad de información y protección de datos 43

Information Governance 43

Financial Information Security 43

Cybersecurity Governance 43

Information Security for Middle Size Enterprises 43

Information Security for all Organizations 43

Comparativo de áreas a evaluar $\quad 44$

Normas peruanas relacionadas a la protección de datos $\quad 44$

Circular g-140 44

Ley de protección de datos personales $\quad 44$

Diseño del modelo de madurez $\quad 45$

Modelo de Madurez $\quad 45$

Fases de madurez $\quad 45$

Niveles de madurez $\quad 46$

Dominios $\quad 46$

$\begin{array}{ll}\text { Datos } & 47\end{array}$

$\begin{array}{ll}\text { Seguridad de información } & 47\end{array}$

$\begin{array}{ll}\text { Riesgos } & 47\end{array}$

$\begin{array}{ll}\text { Organización } & 47\end{array}$

$\begin{array}{ll}\text { Referencias } & 47\end{array}$

$\begin{array}{ll}\text { Estándares } & 47\end{array}$

$\begin{array}{ll}\text { Regulaciones } & 47\end{array}$

$\begin{array}{ll}\text { Criterios } & 48\end{array}$ 
Datos

Seguridad de información

Riesgos

Organización

Preguntas de evaluación

Cálculo de los resultados

Elaboración de la herramienta de evaluación

Sección de inicio

Sección de preguntas por dominio

Sección de resultados

Capítulo 6: Resultados del Proyecto

Juicio de expertos

Expertos

Carlos Horna Vallejos

Lucero Valderrama Valderrama

Víctor Lujan Cabrera

Presentación del modelo de madurez

Resultados del juicio de expertos

Caso de estudio

Micro financieras

Caja Sipán

Crediflorida

COOPSCB

EDAPROSPO

MiBanco

Resultados del caso de estudio

Plan de Continuidad

Objetivo

Objetivos específicos

Roles de proyecto

Resumen de actividades

Segmentación del sector micro financiero

Clasificación de micro financieras 
Adaptación a normas extranjeras

Retorno de inversión $\quad 75$

Capítulo 7: Gestión del Proyecto $\quad 77$

$\begin{array}{ll}\text { Gestión del cronograma } & 78\end{array}$

Gestión de recursos humanos $\quad 81$

Gestión de riesgos $\quad 82$

Lecciones aprendidas $\quad 82$

Definir un límite de tiempo interno para la finalización de entregables 83

Necesidad de un repositorio de información interno 83

Elaborar documentos de control interno $\quad 83$

$\begin{array}{ll}\text { Conclusiones } & 84\end{array}$

Recomendaciones $\quad 85$

Glosario $\quad 86$

$\begin{array}{ll}\text { Bibliografía } & 87\end{array}$ 


\section{Índice de Tablas}

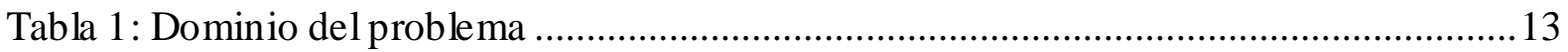

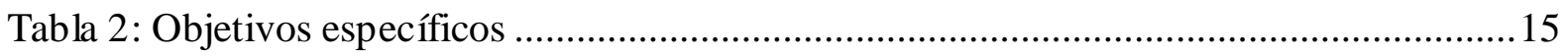

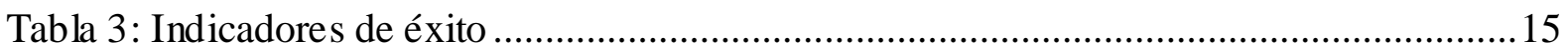

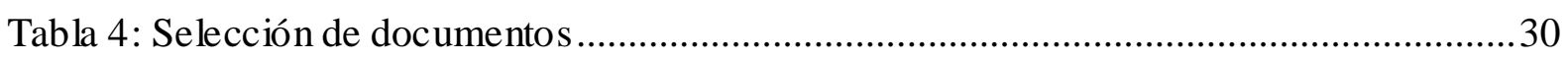

Tabla 5: Leyes y regulaciones de protección de datos .........................................................34

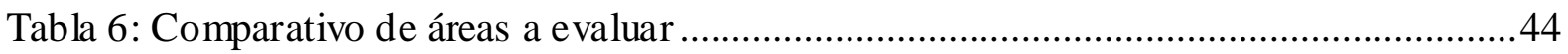

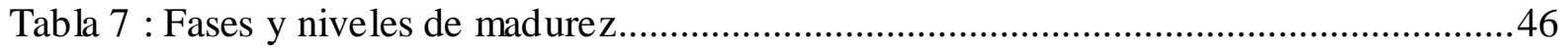

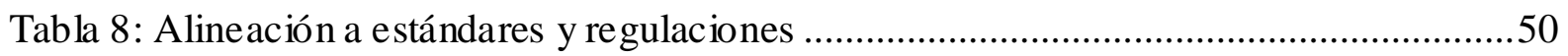

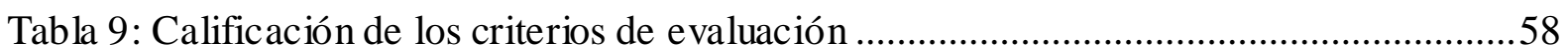

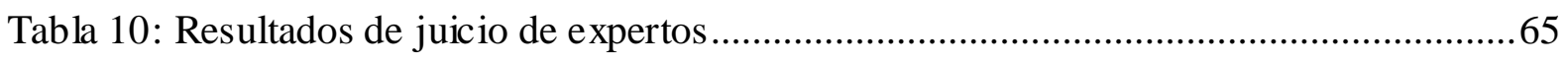

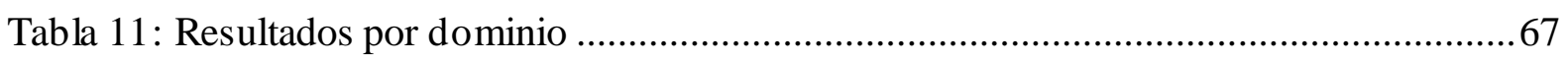

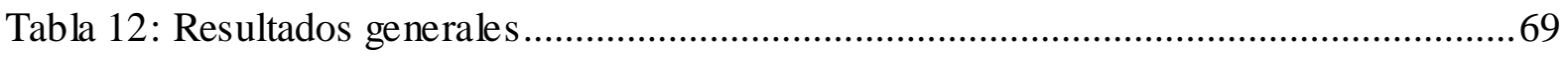

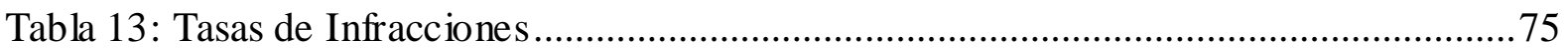

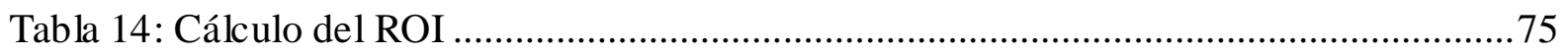

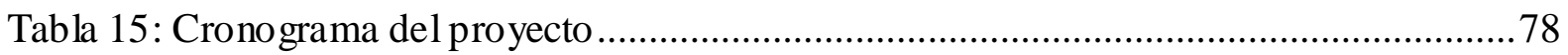

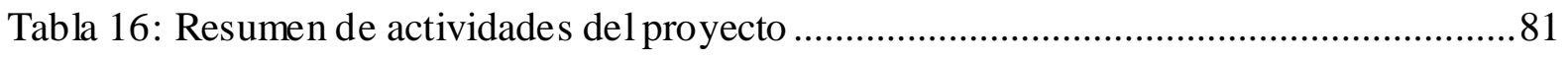

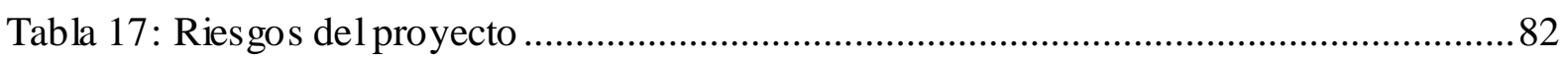




\section{Lista de Figuras}

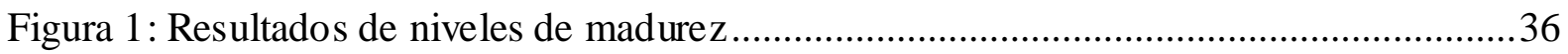

Figura 2: Estructura jerárquica de índices de evaluación ....................................................36

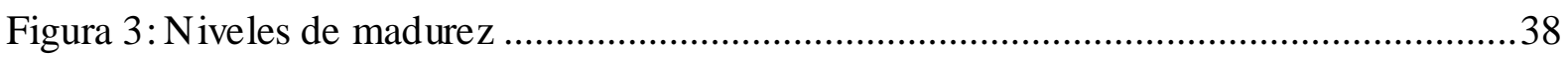

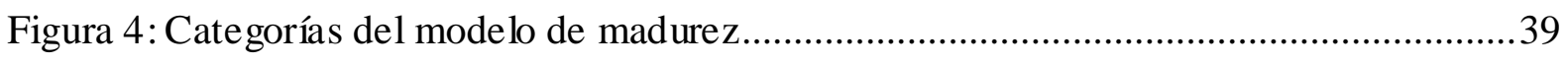

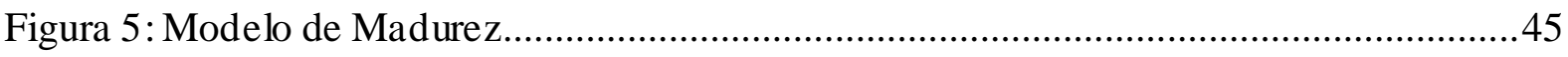

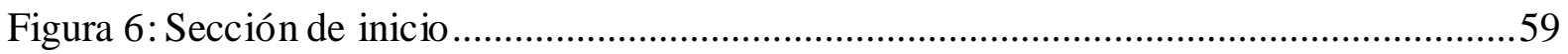

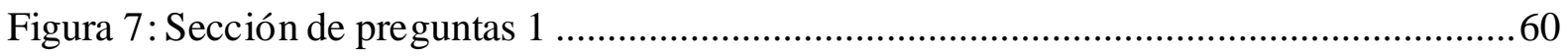

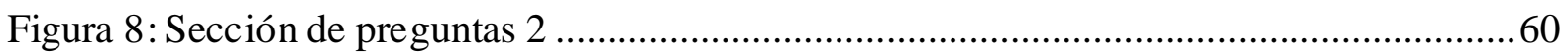

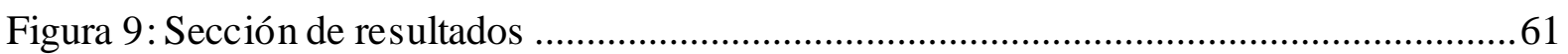

Figura 9: Modelo de madurez de protección de datos personales .........................................64

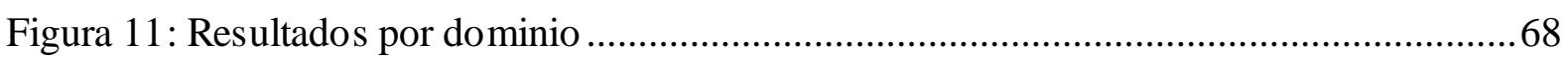

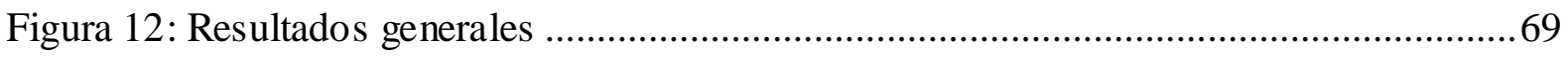

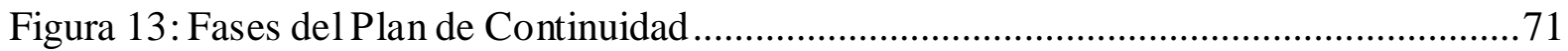




\section{Introducción}

El sector micro financiero es un elemento estratégico en la economía de los países en desarrollo, ya que facilita la integración y el desarrollo de todas las clases sociales y permite el crecimiento económico. En este punto, el crecimiento de los datos es alto cada día en el sector como el micro financiero, como resultado de las transacciones y operaciones que se llevan a cabo con estas compañías diariamente. Por lo tanto, es necesario un manejo adecuado de las políticas de privacidad de datos personales, ya que, de lo contrario, cumplirá con las leyes y regulaciones de protección de datos personales y permitirá tomar información de calidad para la toma de decisiones y la mejora de procesos.

El presente estudio propone un modelo de madurez de protección de datos personales basado en estándares internacionales de privacidad y seguridad de la información, que también revela las capacidades de protección de datos personales en las organizaciones. Finalmente, se propone una herramienta de evaluación de diagnóstico y rastreo que se llevó a cabo para cinco empresas del sector micro financiero y se analizaron los resultados obtenidos para validar el modelo y ayudar al éxito de las iniciativas de protección de datos.

El documento se consolida en siete capítulos: El primer capítulo determina el punto de inicio del proyecto, así como los objetivos e indicadores y los aspectos generales del mismo. El segundo capítulo describe el cumplimiento de los Student Outcomes que la UPC ha desarrollado en nosotros para el desarrollo del proyecto. En el tercer capítulo se desarrolla el marco teórico del proyecto, en el cual se encuentran las descripciones de los conceptos necesarios para tener un alto nivel de entendimiento del proyecto. El cuarto capítulo incluye la revisión de la literatura referida al Estado del Arte, la cual ha requerido de una exhaustiva investigación de proyectos pasados, que giren en torno al proyecto presentado. En el quinto capítulo se muestra la construcción del modelo de madurez, además del sustento de las fuentes de información necesarias y alineadas al mismo. En el sexto capítulo se describen el producto final, así como la herramienta para su uso, aplicándolo en un caso de estudio que sirva para medir el nivel de cinco micro financieras del Perú. El séptimo capítulo se 
desarrolló con la finalidad de determinar la gestión del proyecto, involucrando el tiempo, personal y riesgos. 


\section{Capítulo 1. Definición del Proyecto}

En este capítulo se presenta la necesidad de un modelo de madurez que permita medir el nivel de capacidad de protección de datos personales en una organización, tomando como consideración las recomendaciones brindadas por estándares internacionales y siguiendo las normas peruanas pertinentes. Definiendo el modelo desde el estado actual de la empresa hasta una correcta gestión de la información, se busca que las micro financieras tengan conocimiento de cuán comprometidas están con los datos sensibles que manejan de sus clientes. Además, se plantean los objetivos generales y específicos del proyecto, así como, los indicadores de éxito y los riesgos del mismo durante su desarrollo. Por último, se presenta el alcance del proyecto. 


\section{Objeto de Estudio}

El sector micro financiero ha cobrado mayor fuerza en el país. Los créditos ofrecidos por una entidad madura, posicionada estratégicamente y con una organización estructurada pueden llegar a generar una rentabilidad superior al 20\% anual. La aceptación con la que cuenta las entidades de este sector es muy alta y una sanción por parte del estado puede impactar gravemente a la empresa tanto en la reputación como en la economía de la organización. Por ello se requiere un modelo que permita evaluar el nivel de madurez que tienen las organizaciones en cuanto al cumplimiento de ley reguladora de protección de datos que sirva de referencia.

\section{Dominio del problema}

El dominio del problema considerado para el presente proyecto es el siguiente:

Tabla 1: Dominio del problema

\begin{tabular}{|c|c|}
\hline Problema & Causas \\
\hline $\begin{array}{l}\text { - Debido al desconocimiento de sus } \\
\text { deberes y derechos sobre la } \\
\text { privacidad de sus datos y la de sus } \\
\text { clientes, las empresas son } \\
\text { sancionadas por incumplir la ley de } \\
\text { protección de datos personales. Por } \\
\text { ejemplo, según un estudio realizado } \\
\text { en junio de } 2016 \text { por Iron Mountain } \\
\text { y PwC, el } 41 \% \text { de las empresas } \\
\text { medianas en Europa incumplen la } \\
\text { Regulación General de Protección } \\
\text { de Datos } \\
\text { No existe una metodología mediante } \\
\text { la cual sea posible comprobar que } \\
\text { empresas acatan adecuadamente la } \\
\text { ley de protección de datos personales }\end{array}$ & $\begin{array}{l}\text { - El INEI afirma que en el } 2012 \text { el } \\
87.3 \% \text { de las empresas en el país } \\
\text { eran informales. Además, hasta } \\
\text { agosto del año pasado el diario } \\
\text { Gestión sostiene que “... pese a } \\
\text { que estas (PYMEs) generan el } \\
21.6 \% \text { del PBI, cuatro de cada } \\
\text { cinco PYMEs son informales". } \\
\text { - Las empresas que cotizan en bolsa } \\
\text { y el sector bancario, son los } \\
\text { sectores más avanzados en este } \\
\text { tema, debido a la regulación de la } \\
\text { SBS. } \\
\text { Hasta fines del } 2014 \text { el 90\% de las } \\
\text { empresas (medianas y pequeñas) } \\
\text { no adquieren servicios de } \\
\text { consultoría en temas de seguridad. } \\
\text { Sin embargo, cerca de 10,0000 } \\
\text { empresas grandes sí adquieren este } \\
\text { servicio, indicó el CEO de Ernst \& } \\
\text { Young. }\end{array}$ \\
\hline
\end{tabular}

Fuente: Elaboración Propia 


\section{Planteamiento del problema}

La finalidad del proyecto es diseñar un modelo de madurez que permita medir el nivel de cumplimiento de la ley de protección de datos personales en las empresas del sector micro financiero en el Perú. El modelo es validado mediante una herramienta aplicada a los procesos relacionados con la gestión de información de las empresas.

La propuesta del modelo a diseñar permitirá a las organizaciones obtener los siguientes beneficios:

Los beneficios que se obtendrán son:

Beneficios Cualitativos:

- Mejor nivel reputacional.

- Integridad, disponibilidad y confidencialidad de la información.

- Capacidad de respuesta ante cambios legislativos.

Beneficios Cuantitativos:

- Reducción de pérdidas financieras por incumplimiento de leyes.

\section{Objetivos del Proyecto}

\section{Objetivo general}

Implementar un modelo de madurez organizacional que permita medir el nivel de capacidad de protección de datos personales, para el sector micro financiero peruano. 


\section{Objetivos específicos}

Tabla 2: Objetivos específicos

\begin{tabular}{|c|lll|}
\hline $\begin{array}{c}\text { Código del } \\
\text { Objetivo }\end{array}$ & \multicolumn{4}{|c|}{ Indicadores de Éxito } \\
\hline OE1 & $\begin{array}{l}\text { Analizar el estado del arte de los modelos de madurez de } \\
\text { protección de datos y seguridad de la información }\end{array}$ \\
\hline OE2 & $\begin{array}{l}\text { Diseñar el modelo de madurez siguiendo estándares ISO y } \\
\text { regulaciones peruanas. }\end{array}$ \\
\hline OE3 & Validar el modelo de madurez por juicio de expertos. & \\
\hline OE4 & $\begin{array}{l}\text { Proponer una cartera de proyectos alineados a la } \\
\text { implementación. }\end{array}$ \\
\hline
\end{tabular}

Fuente: Elaboración propia

\section{Indicadores de éxito}

Tabla 3: Indicadores de éxito

\begin{tabular}{|c|l|c|}
\hline $\begin{array}{c}\text { Código del } \\
\text { Objetivo }\end{array}$ & \multicolumn{1}{|c|}{ Indicadores de Éxito } & $\begin{array}{c}\text { Objetivos } \\
\text { Específicos }\end{array}$ \\
\hline IE1 & $\begin{array}{l}\text { Aprobación del estado del arte por parte } \\
\text { del profesor cliente y revisor. }\end{array}$ & OE1 \\
\hline IE2 & $\begin{array}{l}\text { Acta de reunión con la aprobación del } \\
\text { diseño del modelo de madurez. }\end{array}$ & OE2 \\
\hline IE3 & $\begin{array}{l}\text { Acta de conformidad del cliente sobre la } \\
\text { validación del modelo de madurez. }\end{array}$ & OE3 \\
\hline IE4 & $\begin{array}{l}\text { Acta de conformidad del cliente del } \\
\text { plan de continuidad del proyecto }\end{array}$ & OE4 \\
\hline
\end{tabular}

Fuente: Elaboración propia

\section{Alcance del proyecto}

El alcance del proyecto incluye:

- Validación del modelo para medir el nivel de madurez y cumplimiento de la gestión de la privacidad de datos según estándares de la ISO 27001.

- Implementación del modelo de madurez en una herramienta de diagnóstico organizacional.

- Modelo y herramienta orientado al sector micro financiero peruano. 
- Las exclusiones del proyecto son las siguientes:

- Implementación en empresas grandes.

- Soporte del modelo luego de firmarse el acta de conformidad.

- Proceso de escalamiento en el nivel de cumplimiento (post diagnóstico). 


\section{Capítulo 2: Student Outcomes}

En este capítulo se presenta la evidencia con la cual se logra cumplir con los Student Outcomes definidos por la acreditadora internacional ABET. 


\section{Competencias específicas}

\section{Student Outcome A}

Propone soluciones en sistemas de información aplicando principios de matemática, ciencias, computación e ingeniería a problemas de ingeniería de sistemas de información.

\section{ISO/IEC 27002 - CMMI:}

Nuestra propuesta de solución, el modelo de madurez de protección de datos personales se basa en diferentes estándares internacionales entre los cuales destaca la ISO / IEC 27002 relacionada directamente a la Seguridad de Información. Además, para la estructura del modelo de madurez se tomó como referencia otros modelos de madurez los cuales se basan en CMMI. Además se realiza un cálculo matemático para determinar el resultado de la micro financiera.

$$
\begin{aligned}
& \text { Puntaje }_{\text {dominio }}=\frac{\int_{c}^{c} p_{\text {criterio }} * p_{\text {opción }}}{\text { Puntaje }_{\max }} * 100
\end{aligned}
$$

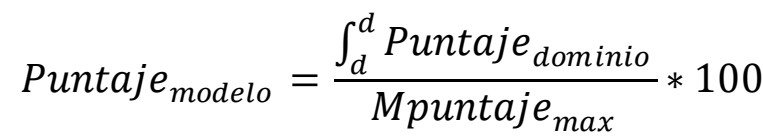

$$
\begin{aligned}
& \text { c: Preguntas de evaluación } \\
& \text { d: Dominios del modelo } \\
& \text { pcriterio:Peso de criterio } \\
& \text { pcriterio:Peso de opción } \\
& \text { Puntajemax: Puntaje máximo del dominio } \\
& \text { Mpuntajemax: Puntaje máximo del puntaje }
\end{aligned}
$$




\section{Student Outcome B}

Formula y administra proyectos y experimentos en base al análisis e interpretación de datos relevantes en la implementación de sistemas de información.

\section{Propuesta de Modelo}

Se analizó la problemática del incumplimiento de la ley de protección de datos personales en las pequeñas y medianas empresas. Para dar solución a este problema se propuso el presente proyecto, el cual tiene como objetivo mejorar los índices de cumplimiento de las organizaciones del sector micro financiero peruano. El proyecto se maneja siguiendo los lineamientos de la gestión de proyectos de TI.

\section{Student Outcome C}

Capacidad para diseñar un sistema, componente o proceso para satisfacer las necesidades deseadas dentro de restricciones realistas tales como económico, ambiental, social, político, ético, salud y seguridad, manufacturabilidad y sostenibilidad

\section{Propuesta de Modelo}

El modelo de madurez se diseñó tomando en consideración factores como el poder económico de las organizaciones objetivo, en este caso las micro financieras, las cuales manejan una gran cantidad de datos personales los cuales deben ser protegidos, pero no tienen los mismos ingresos que un banco bien posicionado en el mercado. Por esta razón, el objetivo del modelo de madurez es que se beneficie a la empresa no solo con el cumplimiento de la ley, sino también generando una cultura de seguridad de información en la organización, brindando información sobre que controles deben priorizar, dentro de sus capacidades económicas, lo que permita mejorar su nivel de protección de datos personales y que puedan brindar esa sensación de seguridad a sus clientes. 


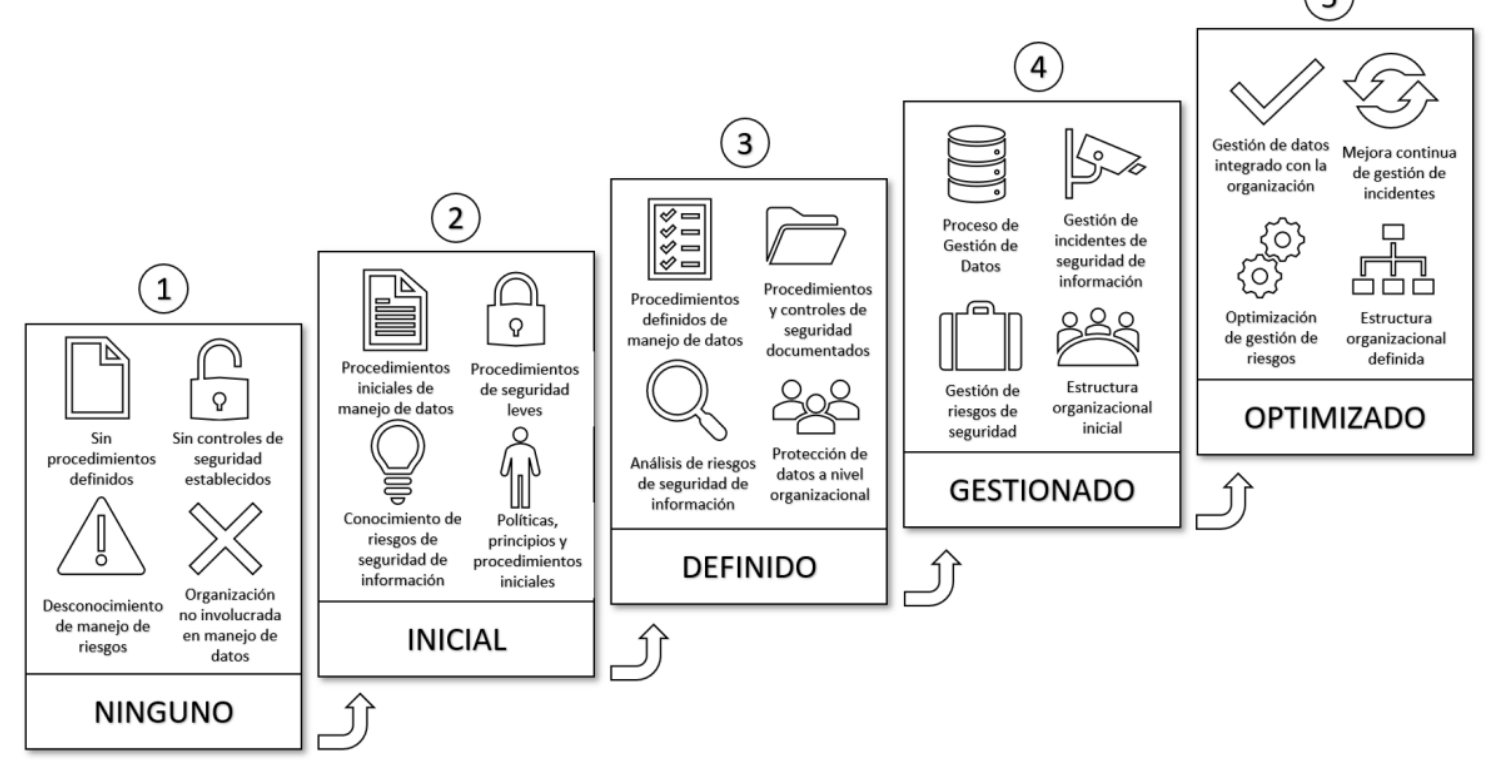

\section{Student Outcome D}

Participa en equipos multidisciplinarios liderando o desarrollando sus tareas eficientemente con profesionales de diferentes especialidades o dominios de aplicación.

\section{Representantes de Micro financieras}

Como parte del desarrollo del proyecto se consultó a un profesional de diseño gráfico sobre la presentación gráfica del modelo de madurez. Además, para la validación del modelo se realizaron reuniones con expertos en:

- Sector objetivo: Jefe de Riesgos con experiencia en tres cajas municipales.

- Regulación: Supervisora de Sistemas y Tecnología de la SBS.

- Protección de datos personales: Consultor encargado del desarrollo de la directiva de seguridad para ley 29733

\section{Student Outcome E}

Identifica y analiza problemas de negocio o tecnológicos dentro del ciclo de vida de un sistema de información con alcance empresarial o inter empresarial.

\section{Análisis de situación actual}

El principal problema encontrado en la situación actual de la protección de datos personales en el país radica en que las grandes empresas poseen el poder económico para implementar 
controles, contratar consultoras de seguridad de información, realizar auditorías externas, etc. Sin embargo, las pequeñas empresas también deben cumplir la ley de protección de datos personales y estas no cuentan con los mismos recursos que sus contrapartes superiores, esta es la necesidad que busca solucionar el presente trabajo.

\section{Student Outcome F}

Propone soluciones en sistemas de información con responsabilidad profesional y ética.

\section{Referencias bibliográficas}

En la realización del proyecto se tomó como referencia trabajos previos relacionados al tema del proyecto, tanto en la fase de investigación, estado del arte, marco teórico, etc. En todos los casos se citó a las fuentes, artículos académicos, páginas web, libros y personas naturales. Aunque el presente trabajo presenta un caso de estudio enfocado en cinco micro financieras, estas fueron voluntarias para realizar la evaluación. Los resultados fueron completamente reales y transparentes sin beneficiar a ninguna de las organizaciones evaluadas.

\section{Student Outcome G}

Comunica ideas o resultados orales o escritos con claridad y efectividad a públicos de diferentes especialidades y niveles jerárquicos.

\section{Reuniones con comité, profesor cliente y profesor gerente}

La comunicación escrita en el proyecto se evidencia en los entregables de gestión, en la elaboración del artículo académico del proyecto, en la redacción de la memoria del proyecto, en el cuestionario de evaluación y otros entregables, los cuales deben ser comprensibles para los revisores.

Durante el proyecto se realizaron presentaciones de los objetivos al comité y la presentación del modelo de madurez y la herramienta de evaluación a los expertos para su validación. Todas están presentaciones tuvieron como objetivo transmitir claramente la idea de nuestro proyecto.

\section{Student Outcome H}

Identifica el impacto de las soluciones en sistemas de información en el contexto global, económico y del entorno en la sociedad. 


\section{Beneficios del modelo}

Los beneficios de nuestro proyecto impactan, en el contexto económico, evitando multas debido a la mejora de los índices de cumplimiento de la ley 29733, además de los gastos generados por la pérdida o filtración de información. En la sociedad, mejorando la percepción de seguridad de los clientes de las micro financieras sobre la protección de sus datos personales.

\section{Student Outcome I}

Actualiza los conocimientos en metodologías, técnicas, herramientas por ser necesarios para mantener la vigencia en el desarrollo de sistemas de información.

\section{Estándares y normas regulatorias}

Para el diseño del modelo de madurez, no solo se consideró la ley de protección de datos personales y la circular g-140 de la SBS, sino que se tomaron los siguientes estándares mundialmente aceptados:

- Seguridad de información: ISO / IEC 27002

- Privacidad: ISO / IEC 29100

- Seguridad en sistemas financieros: ISO / TR 17944

\section{Student Outcome J}

Analiza hechos del mundo contemporáneo identificando el impacto en el desempeño profesional del ingeniero de sistemas de información.

\section{Impacto del modelo propuesto}

Debido a la necesidad de elevar los índices de cumplimiento de la ley en las organizaciones y mejorar la cultura de seguridad de información. El modelo de madurez propuesto promueve la contratación de ingenieros de sistemas de información con perfiles orientados a la seguridad de información que puedan ayudar a las organizaciones a mejorar su nivel de protección de datos personales basada en la evaluación del modelo de madurez.

\section{Student Outcome K}

Utiliza técnicas y herramientas de última generación en el desarrollo de sistemas de información. 


\section{Estándares}

Para el desarrollo del modelo de madurez se consideraron los estándares ISO / IEC 27002:2013 Seguridad de Información, ISO / IEC 29100 Framework de Privacidad. Técnicas de diseño de modelo de madurez tomando como referencias otros modelos de madurez de artículos académicos relacionados a seguridad de información con un período de antigüedad no mayor a tres años.

\section{Competencias Generales}

\section{Comunicación escrita}

Comunicación escrita es la capacidad para construir mensajes con contenido relevante, argumentos sólidos y claramente conectados adecuados a diversos propósitos y audiencia.

\section{Aplicación}

Durante el desarrollo de este trabajo se utilizó la comunicación escrita en la redacción de los diferentes entregables del proyecto y en la interacción con otros responsables e interesados del proyecto. Los documentos fueron redactados siguiendo un orden secuencial y una estructura definida utilizando lenguaje formal y siendo concisos según la necesidad del documento con el fin de transmitir de manera clara la idea de nuestro trabajo. De la misma manera al interactuar con personas internas y externas al proyecto, usando lenguaje coloquial mediante correos electrónicos y mensajes de textos.

\section{Comunicación oral}

Capacidad para transmitir oralmente mensajes de manera eficaz dirigidos a diversas audiencias, usando diferentes herramientas que faciliten su comprensión y el logro del propósito.

\section{Aplicación}

La capacidad de comunicación oral fue desarrollada durante este trabajo en la presentación de los objetivos al comité en las que debido al tiempo fue necesario hacer uso de nuestra capacidad de síntesis con el apoyo visual de gráficos. También en las coordinaciones y presentaciones del modelo de madurez a los expertos para la fase de validación y en las interacciones con nuestros profesores gerente y asesor. 


\section{Ciudadanía}

Capacidad para valorar la convivencia humana en sociedades plurales, reflexionando acerca de las dimensiones morales de las propias acciones y decisiones, asumiendo la responsabilidad por las consecuencias en el marco del respeto de los derechos y deberes ciudadanos.

\section{Aplicación}

Para el caso de estudio en el que se evaluó a cinco micro financieras se acordó con los contactos de las mismas que los resultados serían usados solo para fines académicos, que no serán compartidos con terceros, a menos que sea de manera anónima, es decir, que los resultados se presentarían con un nombre general como "micro financiera 1" o "micro financiera A".

\section{Pensamiento innovador}

Capacidad para detectar necesidades y oportunidades para generar proyectos o propuestas innovadoras, viables y rentables. Planifica y toma decisiones eficientes orientadas al objetivo del proyecto.

\section{Aplicación}

Se seleccionó como sector objetivo de la solución propuesta, al sector micro financiero, debido a que su capacidad económica es menor que la de los grandes bancos del país. Por consiguiente, no poseen los recursos suficientes para contratar constantemente los servicios de consultoras de seguridad de información.

El beneficio para el sector es minimizar e idealmente, eliminar las multas por incumplimiento de la ley de protección de datos personales.

\section{Pensamiento crítico}

Capacidad para explorar de manera exhaustiva problemas, ideas o eventos para formular conclusiones u opiniones sólidamente justificadas.

\section{Aplicación}

Se evaluó la problemática de incumplimiento no solo a nivel local, sino en diferentes lugares del mundo, analizando datos estadísticos recopilados por consultoras de nivel mundial. Una 
vez hecho esto se consideró necesario utilizar estándares internacionales como referencia para el modelo de madurez en el contexto de las normas y regulaciones peruanas.

\section{Razonamiento cuantitativo}

Capacidad para interpretar, representar, comunicar y utilizar información cuantitativa diversa en situaciones de contexto real. Incluye calcular, razonar, emitir juicios y tomar decisiones con base en esta información cuantitativa

\section{Aplicación}

Una vez realizadas las evaluaciones del caso de estudio se procedió a analizar e interpretar los resultados para definir las conclusiones relacionadas al sector micro financiero y plantear mejoras a la versión actual del modelo de madurez.

\section{Manejo de la información}

Capacidad de identificar la información necesaria, así como de buscarla, seleccionarla, evaluarla y usarla éticamente, con la finalidad de resolver un problema.

\section{Aplicación}

Se seleccionaron artículos académicos para la fase de investigación y fueron utilizados como fuente bibliográfica para el diseño del modelo de madurez. También fueron seleccionados estándares internacionales como referencia para determinar los criterios del modelo. Todos estos trabajos utilizados dentro del desarrollo del proyecto fueron citados con el fin de reconocer el trabajo hecho por otros profesionales. 


\section{Capítulo 3. Marco Teórico}

En este capítulo se describen los conceptos necesarios para el desarrollo del proyecto. La información se basa en estándares y regulaciones utilizados en la construcción del modelo de madurez. 


\section{Circular g-140 - 2009}

Norma regulatoria emitida por la Superintendencia de Banca y Seguros la cual establece los criterios mínimos para una adecuada gestión de seguridad de la información que toma como referencia estándares internacionales como la ISO 17799 y la ISO 27001, la cual tiene dentro de su alcance las Cajas Municipales de Ahorro y Crédito (CMAC), el Banco de la Nación, el Banco Agropecuario, entre otras.

\section{ISO 17944}

Brinda un framework que trata la seguridad necesaria para la industria financiera. Consiste en un conjunto de ítems claves de seguridad y para cada ítem se presentan estándares relevantes.

\section{ISO 27002}

La ISO 27002 brinda guías para los estándares de seguridad de la información y la gestión de la seguridad de la información incluyendo, la selección, implementación y gestión de controles tomando en consideración el entorno de seguridad de información de la organización.

\section{ISO 29100}

Estándar internacional que brinda un framework de alto nivel para la protección de información personal dentro de los sistemas de tecnología de información y comunicación. Presenta un framework de privacidad tanto a nivel de procedimientos, técnicas y organización.

\section{Ley de protección de datos personales}

La ley 29733 de Protección de Datos Personales del Perú tiene como objetivo proteger todos los datos de las personas naturales gestionados por las compañías: clientes, colaboradores y proveedores, entre otros. Para ello se requiere la implementación de un marco integrado de medidas técnicas, organizacionales y legales. 


\section{Modelo de madurez}

Un modelo de madurez es un conjunto estructurado de elementos (buenas prácticas, herramientas de medición, criterios de análisis, etc.), que permite identificar las capacidades instaladas en dirección de proyectos en la organización, compararlas con estándares, identificar vacíos o debilidades y establecer procesos de mejora continua.

\section{PYME}

Es el acrónimo de pequeña y mediana empresa. Estas poseen entre 11 y 200 trabajadores y sus ventas anuales se encuentran entre 125 mil y 20 millones de dólares. 


\section{Capítulo 4: Estado del Arte}

En este capítulo se muestra el proceso de elaboración del estado del arte de los diferentes factores que nos servirán para proponer nuestro modelo de madurez organizacional, abarcando la selección de documentos y el análisis de estos. 


\section{Selección de documentos}

Para solucionar la problemática planteada, es necesario responder las siguientes preguntas de investigación: (añadir preguntas)

Para atender estas preguntas se realizó una investigación en la sección journals de los siguientes bancos de artículos académicos: IEEE Xplore Digital Library, Scopus y Siencedirect. La estrategia de investigación contó con dos fases la primera utilizando palabras claves relacionadas directamente al tema del proyecto, como: "data protection", "personal data protection", "privacy", "maturity model", "micro financial" e "ISO 27001"; tanto en el título del artículo como en el resumen (abstract) del mismo. La finalidad de esta primera fase, además de seleccionar artículos acordes a nuestro tema, fue encontrar palabras relacionadas que nos pudieran ayudar en la segunda fase, las palabras obtenidas fueron: "information security", "regulatory", "compliance", "law", "computer law", "financial data". Se utilizaron combinaciones de las palabras claves mencionadas, además de artículos citados para completar la selección. El período de búsqueda abarcó, en su mayoría, los años 2014, 2015, 2016 y el año en curso.

Finalmente fueron seleccionados 28 artículos académicos los cuales se muestran en la siguiente tabla:

Tabla 4: Selección de documentos

\begin{tabular}{|c|c|c|c|c|}
\hline Núm & Título & Autor & Journal & Año \\
\hline 1 & $\begin{array}{c}\text { A maturity model for } \\
\text { information governance }\end{array}$ & $\begin{array}{c}\text { Diogo Proença, Ricardo } \\
\text { Vieira, José Borbinha }\end{array}$ & $\begin{array}{c}\text { Information } \\
\text { Systems and } \\
\text { Technologies }\end{array}$ & 2016 \\
\hline 2 & $\begin{array}{c}\text { Compliance to Personal } \\
\text { Data Protection } \\
\text { Principles: A Study of } \\
\text { How Organizations } \\
\text { Frame Privacy Policy } \\
\text { Notices }\end{array}$ & $\begin{array}{c}\text { Hui Na Chua, Anthony } \\
\text { Herbland, Siew Fan } \\
\text { Wong, Younghoon } \\
\text { Chang }\end{array}$ & $\begin{array}{c}\text { Telematics } \\
\text { and } \\
\text { Informatics }\end{array}$ & 2017 \\
\hline 3 & $\begin{array}{c}\text { Study on financial- } \\
\text { sector information } \\
\text { security level } \\
\text { assessment and } \\
\text { improvement } \\
\text { anticipation model }\end{array}$ & $\begin{array}{c}\text { Young-Rai Park, Yoon- } \\
\text { Chul Choy, Won-Sung } \\
\text { Shon }\end{array}$ & $\begin{array}{c}\text { Engineering } \\
\text { Research } \\
\text { Support } \\
\text { Society }\end{array}$ & 2014 \\
\hline 4 & $\begin{array}{c}\text { Modelling Cyber } \\
\text { Security Governance }\end{array}$ & $\begin{array}{c}\text { Rossouw de Bruin, SH } \\
\text { von Solms }\end{array}$ & $\begin{array}{c}\text { Institute of } \\
\text { Electrical and }\end{array}$ & 2016 \\
\hline
\end{tabular}




\begin{tabular}{|c|c|c|c|c|}
\hline & Maturity & & $\begin{array}{l}\text { Electronics } \\
\text { Engineers }\end{array}$ & \\
\hline 5 & $\begin{array}{c}\text { Privacy Engineering: } \\
\text { Shaping an Emerging } \\
\text { Field of Research and } \\
\text { Practice }\end{array}$ & $\begin{array}{c}\text { Seda Gürses, Jose M. } \\
\text { del Alamo }\end{array}$ & $\begin{array}{l}\text { Institute of } \\
\text { Electrical and } \\
\text { Electronics } \\
\text { Engineers }\end{array}$ & 2016 \\
\hline 6 & $\begin{array}{l}\text { Privacy and security: } \\
\text { Can you engineer } \\
\text { privacy? The challenges } \\
\text { and potential } \\
\text { approaches to applying } \\
\text { privacy research in } \\
\text { engineering practice }\end{array}$ & Seda Gurses & $\begin{array}{l}\text { Association } \\
\text { for } \\
\text { Computing } \\
\text { Machinery }\end{array}$ & 2016 \\
\hline 7 & $\begin{array}{l}\text { Factors influencing } \\
\text { information security } \\
\text { management in small- } \\
\text { and medium-sized } \\
\text { enterprises: A case } \\
\text { study from Turkey }\end{array}$ & $\begin{array}{c}\text { Ebru Yeniman } \\
\text { Yildirim, Gizem Akalp, } \\
\text { Serpil Aytac, Nuran } \\
\text { Bayram }\end{array}$ & $\begin{array}{l}\text { International } \\
\text { Journal of } \\
\text { Information } \\
\text { Management }\end{array}$ & 2011 \\
\hline 8 & $\begin{array}{l}\text { Nobody puts data in a } \\
\text { corner? Why a new } \\
\text { approach to categorising } \\
\text { personal data is required } \\
\text { for the obligation to } \\
\text { inform }\end{array}$ & $\begin{array}{l}\text { Emma Cradock, Sophie } \\
\text { Stalla-Bourdillon, } \\
\text { David Millard }\end{array}$ & $\begin{array}{l}\text { Computer } \\
\text { Law and } \\
\text { Security } \\
\text { Review }\end{array}$ & 2017 \\
\hline 9 & $\begin{array}{l}\text { A theory of pricing } \\
\text { private data }\end{array}$ & $\begin{array}{c}\text { Chao Li, Daniel Yang } \\
\text { Li, Gerome Miklau, } \\
\text { Dan Suciu }\end{array}$ & $\begin{array}{l}\text { Association } \\
\text { for } \\
\text { Computing } \\
\text { Machinery }\end{array}$ & 2014 \\
\hline 10 & $\begin{array}{c}\text { PISCES: A framework } \\
\text { for privacy by design in } \\
\text { IoT }\end{array}$ & $\begin{array}{l}\text { Noria Foukia, David } \\
\text { Billard, Eduardo Solana }\end{array}$ & $\begin{array}{l}\text { Institute of } \\
\text { Electrical and } \\
\text { Electronics } \\
\text { Engineers }\end{array}$ & 2016 \\
\hline 11 & $\begin{array}{l}\text { Standardization in } \\
\text { personal data protection }\end{array}$ & O. M. Fal & $\begin{array}{c}\text { Cybernetics } \\
\text { and Systems } \\
\text { Analysis }\end{array}$ & 2014 \\
\hline 12 & $\begin{array}{c}\text { Organizational } \\
\text { characteristics } \\
\text { influencing SME } \\
\text { information security } \\
\text { maturity }\end{array}$ & $\begin{array}{l}\text { Frederik Mijnhardt, } \\
\text { Thijs Baars, Marco } \\
\text { Spruit }\end{array}$ & $\begin{array}{l}\text { International } \\
\text { Association } \\
\text { for Computer } \\
\text { Information } \\
\text { Systems }\end{array}$ & 2016 \\
\hline 13 & ISMS-CORAS: A & Kristian Beckers, & $\mathrm{ACM}$ & 2014 \\
\hline
\end{tabular}




\begin{tabular}{|c|c|c|c|c|}
\hline & $\begin{array}{l}\text { structured method for } \\
\text { establishing an ISO } \\
27001 \text { compliant } \\
\text { information security } \\
\text { management system }\end{array}$ & $\begin{array}{l}\text { Maritta Heisel, Bjornar } \\
\text { Solhaug, Ketil Stolen }\end{array}$ & $\begin{array}{c}\text { Transactions } \\
\text { on Database } \\
\text { Systems }\end{array}$ & \\
\hline 15 & $\begin{array}{c}\text { A cyclical evaluation } \\
\text { model of information } \\
\text { security maturity } \\
\text { Approach }\end{array}$ & $\begin{array}{l}\text { Evandro Rigon, Carla } \\
\text { Westphall, Daniel dos } \\
\text { Santos, Carlos } \\
\text { Westphall }\end{array}$ & $\begin{array}{l}\text { Lectures } \\
\text { Notes in } \\
\text { Computer } \\
\text { Science }\end{array}$ & 2014 \\
\hline 16 & $\begin{array}{l}\text { Impact of personal data } \\
\text { protection (PDP) } \\
\text { regulations on } \\
\text { operations workflow }\end{array}$ & $\begin{array}{c}\text { Rajiv Aserkar, A } \\
\text { Seetharaman, Joy } \\
\text { Macaso, Veena Jadhav, } \\
\text { Shivani Inamdar }\end{array}$ & $\begin{array}{c}\text { Human } \\
\text { Systems } \\
\text { Management }\end{array}$ & 2017 \\
\hline 17 & $\begin{array}{l}\text { Post-mortem privacy } \\
\text { 2.0: theory, law, and } \\
\text { technology }\end{array}$ & Edina Harbinja & $\begin{array}{l}\text { International } \\
\text { Review of } \\
\text { Law, } \\
\text { Computers } \\
\text { and } \\
\text { Technology }\end{array}$ & 2017 \\
\hline 18 & $\begin{array}{l}\text { The future of privacy } \\
\text { certification in Europe: } \\
\text { an exploration of } \\
\text { options under article } 42 \\
\text { of the GDPR }\end{array}$ & $\begin{array}{l}\text { Rowena Rodrigues, } \\
\text { David Barnard-Wills, } \\
\text { Paul de Hert, Vagelis } \\
\text { Papakonstantinou }\end{array}$ & $\begin{array}{l}\text { International } \\
\text { Review of } \\
\text { Law, } \\
\text { Computers } \\
\text { and } \\
\text { Technology }\end{array}$ & 2016 \\
\hline 19 & $\begin{array}{l}\text { Financial data breaches } \\
\text { in the U.S. retail } \\
\text { economy: Restoring } \\
\text { confidence in } \\
\text { information technology } \\
\text { security standards }\end{array}$ & $\begin{array}{c}\text { Thomas A. Hemphill, } \\
\text { Phil Longstreet }\end{array}$ & $\begin{array}{l}\text { Technology } \\
\text { in Society }\end{array}$ & 2016 \\
\hline 20 & $\begin{array}{l}\text { Personal data: how } \\
\text { context shapes } \\
\text { consumers' data sharing } \\
\text { with organizations from } \\
\text { various sectors }\end{array}$ & $\begin{array}{c}\text { Bjoern Roeber, Olaf } \\
\text { Rehse, Robert Knorrek, } \\
\text { Benjamin Thomsen }\end{array}$ & $\begin{array}{l}\text { Electronic } \\
\text { Markets }\end{array}$ & 2015 \\
\hline
\end{tabular}




\begin{tabular}{|c|c|c|c|c|}
\hline 21 & $\begin{array}{l}\text { The impact of privacy } \\
\text { and data protection } \\
\text { legislation on the } \\
\text { sharing of intrusion } \\
\text { detection information }\end{array}$ & Steven R. Johnston & $\begin{array}{l}\text { Proceedings } \\
\text { on Recent } \\
\text { Advances in } \\
\text { Intrusion } \\
\text { Detection }\end{array}$ & 2015 \\
\hline 22 & $\begin{array}{l}\text { Information security } \\
\text { culture and information } \\
\text { protection culture: A } \\
\text { validated assessment } \\
\text { instrument }\end{array}$ & $\begin{array}{c}\text { Adele Da Veiga, Nico } \\
\text { Martins }\end{array}$ & $\begin{array}{l}\text { Computer } \\
\text { Law and } \\
\text { Security } \\
\text { Review }\end{array}$ & 2015 \\
\hline 23 & $\begin{array}{l}\text { Perceptions of } \\
\text { controllers on EU data } \\
\text { protection reform: A } \\
\text { Finnish perspective }\end{array}$ & Tomi Mikkonen & $\begin{array}{l}\text { Computer } \\
\text { Law and } \\
\text { Security } \\
\text { Review }\end{array}$ & 2015 \\
\hline 24 & $\begin{array}{l}\text { Thinking of data } \\
\text { protection law's subject } \\
\text { matter as a complex } \\
\text { adaptive system: A } \\
\text { heuristic display }\end{array}$ & $\begin{array}{l}\text { Kunbei Zhang, Aernout } \\
\text { H.J. Schmidt }\end{array}$ & $\begin{array}{l}\text { Computer } \\
\text { Law and } \\
\text { Security } \\
\text { Review }\end{array}$ & 2016 \\
\hline 25 & $\begin{array}{c}\text { Information security } \\
\text { management system } \\
\text { implementation success } \\
\text { factors }\end{array}$ & $\begin{array}{l}\text { Maryam Al-Awadi, } \\
\text { Karen Renaud }\end{array}$ & $\begin{array}{l}\text { Advance } \\
\text { Science } \\
\text { Letters }\end{array}$ & 2016 \\
\hline 26 & $\begin{array}{l}\text { Security and privacy } \\
\text { concerns for Australian } \\
\text { SMEs cloud adoption: } \\
\text { Empirical study of } \\
\text { metropolitan vs regional } \\
\text { SMEs }\end{array}$ & $\begin{array}{c}\text { Ishan Senarathna, } \\
\text { William Yeoh, } \\
\text { Matthew Warren, Scott } \\
\text { Salzman }\end{array}$ & $\begin{array}{l}\text { Australasian } \\
\text { Journal of } \\
\text { Information } \\
\text { Systems }\end{array}$ & 2016 \\
\hline 27 & $\begin{array}{c}\text { The regulatory } \\
\text { challenges of Australian } \\
\text { information security } \\
\text { practice }\end{array}$ & $\begin{array}{l}\text { Mark Burdon, Jodie } \\
\text { Siganto, Lizzie Coles- } \\
\text { Kemp }\end{array}$ & $\begin{array}{l}\text { Computer } \\
\text { Law and } \\
\text { Security } \\
\text { Review }\end{array}$ & 2016 \\
\hline 28 & $\begin{array}{l}\text { Do privacy and data } \\
\text { protection rules apply to } \\
\text { legal persons, and } \\
\text { should they? A proposal } \\
\text { for a two-tiered system }\end{array}$ & B. van der Sloot & $\begin{array}{l}\text { Computer } \\
\text { Law and } \\
\text { Security } \\
\text { Review }\end{array}$ & 2015 \\
\hline
\end{tabular}

Fuente: Elaboración Propia 


\section{Revisión de la literatura}

Las regulaciones sobre privacidad y protección de datos tienen como principal objetivo devolver el control sobre su información personal a los ciudadanos y asegurar que las empresas utilizan esta información solo para los medios que el ciudadano autorizó. Debido a esto las organizaciones deben implementar mecanismos que aseguren el cumplimiento de estas regulaciones.

Tabla 5: Leyes y regulaciones de protección de datos

\begin{tabular}{|c|c|c|c|}
\hline Núm & Ley / Regulación & Acciones / Cumplimiento & Referencia \\
\hline 1 & $\begin{array}{l}\text { Acta de Protección } \\
\text { de Datos } \\
\text { Personales } \\
\text { (PDCA) }\end{array}$ & $\begin{array}{l}\text { Estado del cumplimiento mediante el } \\
\text { análisis de pólizas de privacidad de } 306 \\
\text { organizaciones divididas en } 12 \text { sectores. }\end{array}$ & $\begin{array}{c}\text { Proença et al } \\
2016\end{array}$ \\
\hline 2 & $\begin{array}{l}\text { Regulación } \\
\text { General de } \\
\text { Protección de } \\
\text { Datos (GPDR) }\end{array}$ & $\begin{array}{l}\text { Categorización de datos para mejorar el } \\
\text { nivel de transparencia, algunas categorías } \\
\text { son: contacto físico, contacto virtual, } \\
\text { demográfico y socioeconómico, salud, } \\
\text { política, financiera, preferencia, } \\
\text { ubicación, tráfico, etc. }\end{array}$ & $\begin{array}{c}\text { Cradock et al } \\
2017\end{array}$ \\
\hline 3 & $\begin{array}{l}\text { Protección de } \\
\text { Datos Personales } \\
\text { (General) }\end{array}$ & 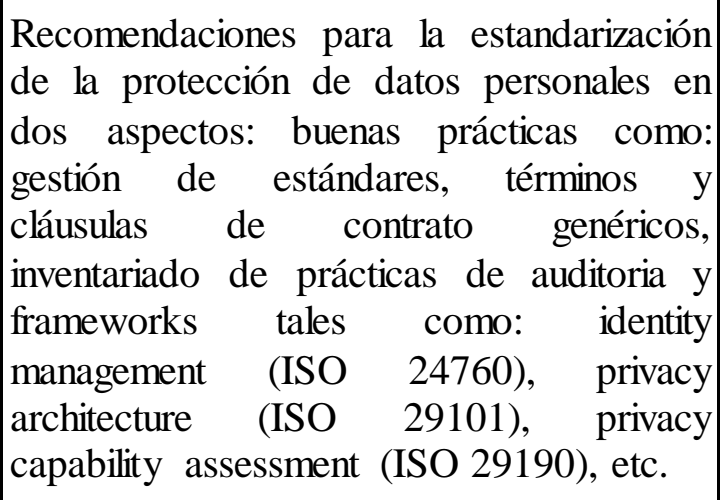 & Fal et al 2014 \\
\hline 4 & $\begin{array}{l}\text { Protección de } \\
\text { Datos Personales } \\
\text { (General) }\end{array}$ & $\begin{array}{l}\text { Identificar las variables independientes } \\
\text { que impactan en el flujo de trabajo } \\
\text { mediante un framework de investigación } \\
\text { algunas de las variables encontradas en } \\
\text { tecnología: data mining, big data, IT } \\
\text { network, en regulaciones: cumplimiento, } \\
\text { costos operativos, procesamiento de } \\
\text { información sensible, etc. }\end{array}$ & $\begin{array}{c}\text { Aserkar et al } \\
2017\end{array}$ \\
\hline 5 & $\begin{array}{l}\text { Regulación } \\
\text { General de } \\
\text { Protección de } \\
\text { Datos (GPDR) }\end{array}$ & $\begin{array}{l}\text { Resume el estado actual de los sellos de } \\
\text { seguridad, certificaciones de procesos y } \\
\text { regulaciones de la Unión Europea. }\end{array}$ & $\begin{array}{l}\text { Rodrigues et } \\
\text { al } 2016\end{array}$ \\
\hline
\end{tabular}




\begin{tabular}{|c|c|c|c|}
\hline 6 & $\begin{array}{l}\text { Regulación } \\
\text { General de } \\
\text { Protección de } \\
\text { Datos (GPDR) }\end{array}$ & $\begin{array}{l}\text { Investiga el nivel de alerta y reacción de } \\
\text { las organizaciones ante la Ley General de } \\
\text { Datos Personales en Finlandia. Utilizó un } \\
\text { método de investigación cuantitativo para } \\
\text { medir la percepción sobre este tema. }\end{array}$ & $\begin{array}{c}\text { Mikkonen et } \\
\text { al } 2014\end{array}$ \\
\hline 7 & $\begin{array}{c}\text { Protección de } \\
\text { Datos Personales } \\
\text { (General) }\end{array}$ & $\begin{array}{l}\text { Investigación sobre si el sujeto de } \\
\text { importancia para la ley de protección de } \\
\text { datos, identificado como Comunidad de } \\
\text { Data Personal (PDC) puede o no, ser } \\
\text { tratada como un Sistema Adaptivo } \\
\text { Complejo (CAS). Se presenta que es un } \\
\text { PDC, que es un CAS, la relación entre } \\
\text { estos y como un PDC puede legar a ser } \\
\text { un CAS. }\end{array}$ & $\begin{array}{l}\text { Zhang et al } \\
2015\end{array}$ \\
\hline 8 & $\begin{array}{c}\text { Protección de } \\
\text { Datos Personales } \\
\text { (General) }\end{array}$ & $\begin{array}{l}\text { El artículo cuestiona si es necesario } \\
\text { considerar a las personas jurídicas dentro } \\
\text { de las leyes de privacidad y protección de } \\
\text { datos. Se define el alcance, cumplimiento } \\
\text { y las preocupaciones de las personas } \\
\text { jurídicas tanto ante los derechos de } \\
\text { privacidad y los derechos de protección } \\
\text { de datos personales. }\end{array}$ & $\begin{array}{c}\text { Van de Sloot } \\
\text { et al } 2015\end{array}$ \\
\hline
\end{tabular}

Fuente: Elaboración propia

\section{Modelos de madurez de seguridad de información}

Un modelo de madurez mide la habilidad o capacidad de mejora continua en una organización en una determinada disciplina, para nuestro caso la más cercana a la protección de datos son los modelos de gestión y evaluación de seguridad de información.

\section{Modelo de madurez para el gobierno de información}

Diogo Proenca, Ricardo Vieira y José Borbinha (2016) indican que un modelo de madurez brinda el camino que se debe tomar para la mejora continua de una organización. En su artículo presentan un modelo para el gobierno de información basado en métodos de desarrollo de modelos de madurez existentes tales como: Asset Management Maturity Model, Enterprise Content Management (ECM) Maturity Model, entre otros. Proponen 5 niveles (Inicial, gestionado, definido, gestionado cuantitativamente y optimizado) a través de 3 dimensiones (Gestión, procesos e infraestructura). 
La evaluación del modelo propuesto fue aplicada a E-ARK, un proyecto de investigación multinacional de big data que tiene como objetivo mejorar los métodos y tecnologías de archivamiento digital, esta evaluación consiste de un cuestionario de 35 preguntas usado para medir las 5 capacidades del modelo general de E-ARK (Pre-ingest, ingest, archival storage and preservation, data management and Access). Los resultados para los 7 pilotos del proyecto se muestran a continuación:

Figura 1: Resultados de niveles de madurez

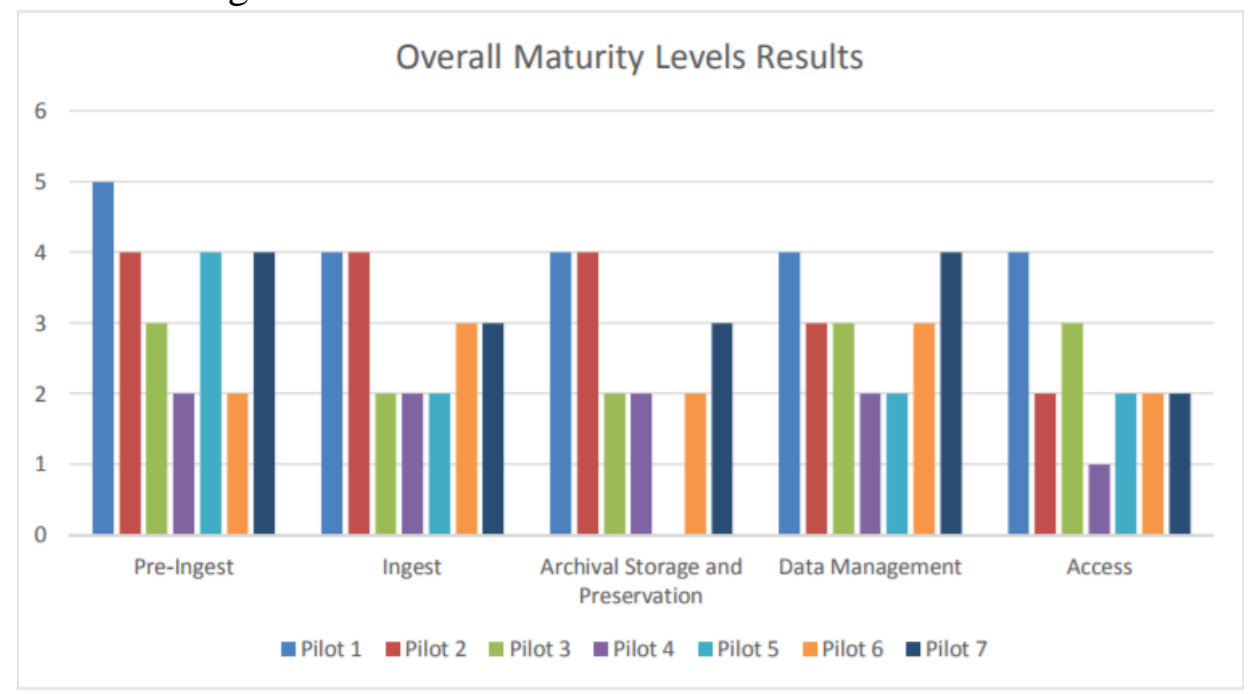

Fuente: Proenca, Diogo y otros (2016)

\section{Modelo de madurez de seguridad de información financiera}

Las amenazas de infracción en el sector financiero se han vuelto más sofisticadas, una consecuencia de esto son los cada vez más frecuentes filtrados masivos de información personal. Por esta razón, Young-Rai Park, Yoon-Chul Choy y Won-Sung Shon (2014) presentan una evaluación de un modelo de madurez de seguridad de información orientado al sector en cuestión.

Previo al diseño de la evaluación, los autores definen y clasifican los índices de evaluación y los controles que son aplicados a estos.

Figura 2: Estructura jerárquica de índices de evaluación 


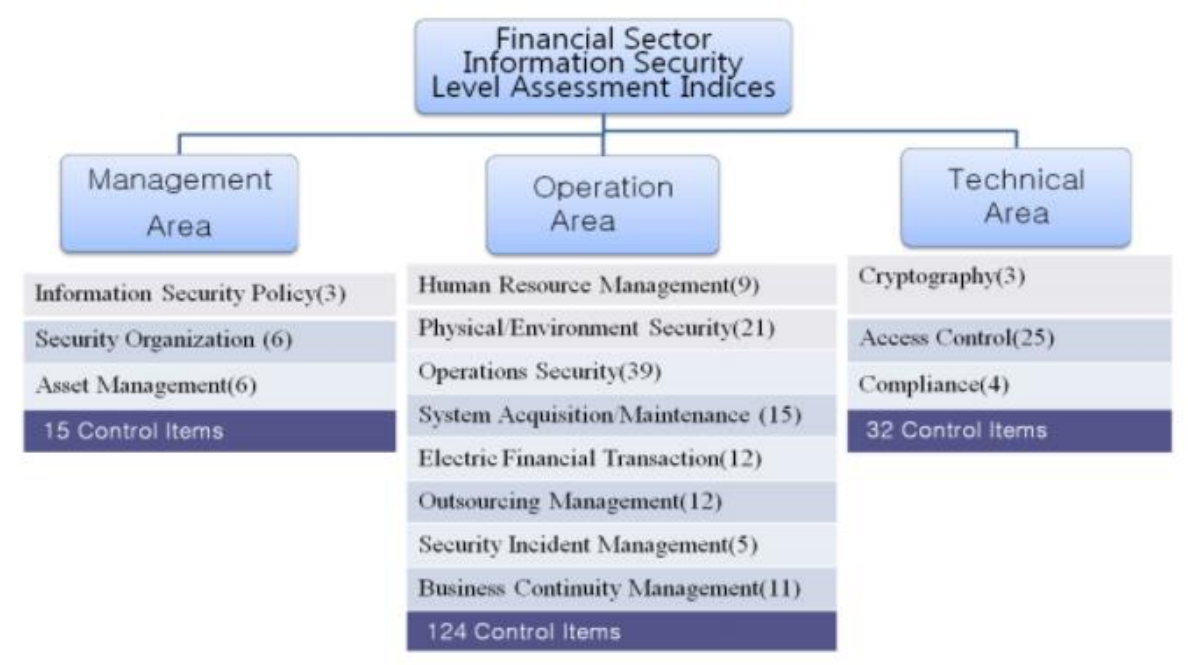

Fuente: Park y otros (2014)

Una vez clasificados los índices de evaluación, definen los niveles de madurez. Los 5 niveles se definen de la siguiente forma: En el nivel 1 solo las políticas documentadas tienen controles, esto se define como que la organización esta "vulnerable" en seguridad de información. En el nivel 2, además de las políticas, también los procesos están documentados, a este nivel se le clasifica como "pobre". En el tercer nivel se suma la documentación de los controles y se le define como "justo". En el siguiente nivel calificado como "bueno", los controles son probados y revisados. Por último, para el nivel 5, todos los anteriores están completamente integrados dentro de la organización y se le considera "excelente". La siguiente tabla resume los niveles de madurez del modelo: 
Figura 3: Niveles de madurez

\begin{tabular}{|c|c|c|c|c|c|}
\hline Levels & Level 1 & Level 2 & Level 3 & Level 4 & Level 5 \\
\hline \multirow{2}{*}{$\begin{array}{c}\text { Maturity } \\
\text { Definition }\end{array}$} & Documented Policy & $\begin{array}{c}\text { Documented } \\
\text { Procedures }\end{array}$ & $\begin{array}{c}\text { Implemented } \\
\text { Procedures } \\
\text { and Controls }\end{array}$ & $\begin{array}{c}\text { Tested and } \\
\text { Reviewed } \\
\text { Procedures } \\
\text { and Controls }\end{array}$ & $\begin{array}{c}\text { Fully } \\
\text { Integrated } \\
\text { Procedures } \\
\text { and Controls }\end{array}$ \\
\cline { 2 - 6 } & Vulnerable & Poor & Fare & Good & Excellent \\
\hline $\begin{array}{c}\text { Score } \\
\text { Range(\%) }\end{array}$ & Score $<40$ & $\begin{array}{c}40<=\text { Score } \\
<60\end{array}$ & $\begin{array}{c}60<=\text { Score }< \\
80\end{array}$ & $\begin{array}{c}80<=\text { Score } \\
<100\end{array}$ & Score $=100$ \\
\hline \multicolumn{2}{|c|}{ Score Calculation Formula } & \multicolumn{4}{|c|}{ Score / perfect point $* 100$} \\
\hline
\end{tabular}

Fuente: Park y otros (2014)

El proceso de evaluación del modelo brinda puntos (1-5) para cada uno de los controles evaluados y el porcentaje obtenido entre la suma del total de puntos obtenidos contra el total de puntos alcanzables nos otorga el nivel de madurez que le corresponde a la organización.

\section{Modelo de madurez de seguridad de información para medianas empresas}

Frederik Mijnhardt, Thijs Baars y Macro Spruit señalan que las pequeñas y medianas empresas tienen, al igual que sus contrapartes más desarrolladas, ciberataques y brechas de seguridad. Además, estas empresas raramente poseen los recursos, tiempo y presupuesto para abordar la complejidad de la mitigación de riesgos. El estándar global para la Seguridad de Información es la serie ISO 27000x, el cual consiste de 9 áreas y 450 items que abarcan los problemas más apremiantes sobre la Seguridad de Información. Sin embargo, debido a la complejidad y extensión de este, las pequeñas y medianas empresas no logran implementar un estándar por completo y terminan con implementaciones ad-hoc para algunas áreas en específico.

Para ayudar a la mejora de la seguridad de información en las pequeñas y medianas empresas tomaremos como ejemplo al modelo de madurez Information Security Focus Area, (ISFAM) este es un método estándar para incrementar la mejora de procesos. Sin embargo, los resultados de las capacidades dependen de las características organizacionales, tales como: tamaño de la organización (número de trabajadores, procesos, infraestructura) y montos de ingresos. Por esta razón modelos como el ISFAM deben tener en cuenta las características organizacionales al momento de evaluar las capacidades de una empresa.

Luego de una revisión de literatura, en bancos como Data Base and Logic Programming (DBLP) y Google Scholar utilizando palabras clave en tres grupos:

- Primer grupo: "Organizational factor", "IT enviroment", "IT complexity”,

- Segundo grupo: "influencing", "impacting"

- Tercer grupo: "information security", "risk management" 
Se determinaron cuatro categorías:

Figura 4: Categorías del modelo de madurez
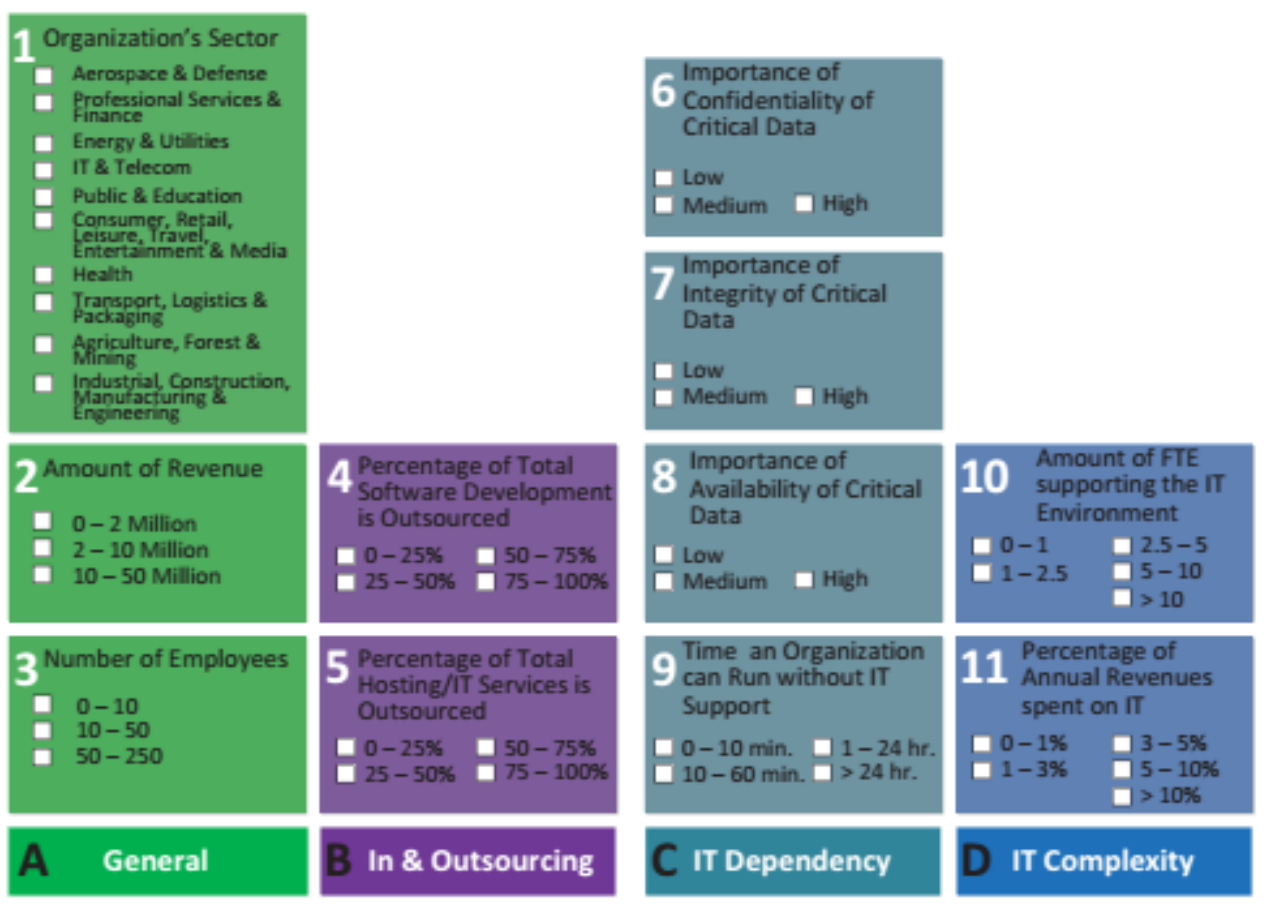

Fuente: Mijnhardt y otros

- General: Estas características brindan una visión global de la organización. La combinación de algunas características de esta categoría como: sector, ganancias, número de empleados nos dan una gran variedad de empresas.

- In \& Outsourcing: La importancia de esta categoría radica en donde se almacena la información crítica de la organización y en la forma en que la empresa puede depender de terceros.

- IT Dependency: Esta categoría indica el nivel de necesidad de las organizaciones por utilizar las buenas prácticas de Seguridad de Información. Las características organizacionales de esta categoría abarcan temas como: confidencialidad, integridad y disponibilidad de información y como se manejarían estos temas sin un área de TI.

- IT Complexity: Por último, la cuarta categoría muestra la relación entre TI y la organización. Algunos temas son cuanto de presupuesto fue asignado a TI, el número de empleados contratados por TI, etc. 


\section{Modelo de madurez de seguridad de información aplicable a todas las organizaciones}

El propósito del autor es presentar una evaluación de madurez sobre la seguridad de información. Esta, está basada en la ISO 27002, la cual provee la situación del manejo y control de acciones que se toman, basadas en riesgos.

El modelo está orientado a los objetivos organizacionales de la empresa, siendo sus principales características las siguientes:

- Nivel 0: Falta completa de cualquier proceso reconocible. La empresa ni siquiera ha reconocido que hay una cuestión que debe abordarse

- Nivel 1: Existen problemas que deben abordarse. Sin embargo, no hay procesos estandarizados; En cambio, hay enfoques ad hoc. El enfoque general de la gestión es desorganizado

- Nivel 2: Procesos repetibles pero intuitivos han sido desarrollados hasta el punto donde procedimientos similares son seguidos por diferentes personas que realizan la misma tarea. No hay formación formal o comunicación de procedimientos estándar, y la responsabilidad es dejada a la persona. Hay un alto grado de confianza en el conocimiento de los individuos $\mathrm{y}$, por lo tanto, los errores son probables

- Nivel 3: La administración monitorea y mide el cumplimiento de los procedimientos y toma acciones donde los procesos parecen no estar funcionando efectivamente. Los procesos están en constante mejora y proporcionan buenas prácticas. La automatización y las herramientas se utilizan de forma limitada o fragmentada

- Nivel 4: La administración monitorea y mide el cumplimiento de los procedimientos y toma acciones donde los procesos parecen no estar funcionando efectivamente. Los procesos están en constante mejora y proporcionan buenas prácticas. La automatización y las herramientas se utilizan de forma limitada o fragmentada. 


\section{Capítulo 5: Desarrollo del Proyecto}

En este capítulo se describe el desarrollo del modelo de madurez, sus fases y los dominios a evaluar, así como la herramienta de evaluación para poder medir los niveles de las micro financieras. 


\section{Investigación y análisis de trabajos similares}

\section{Temas de investigación}

Para la fase previa al desarrollo del modelo de madurez se realizó una investigación considerando temas relacionados directamente al presente trabajo, los temas seleccionados son los siguientes:

\section{Ciberseguridad}

Área que se enfoca en la protección de la información contenida en una computadora o que circula en una red de computadoras. Para lograr esto existen protocoles, técnicas, estándares y leyes que permiten minimizar los riesgos que afecten de manera negativa a la infraestructura tecnológica de una organización y a la información que esta contiene.

\section{Protección de datos}

El tema principal de nuestro proyecto, la protección de datos es comúnmente conocida como la ley designada para proteger la información personal de todas las personas naturales la cual es recolectada, procesada y almacenada dentro del sistema de información de una organización.

\section{Sector financiero y micro financiero}

Debido a que es el sector objetivo de nuestro proyecto, es necesario considerar el impacto de la seguridad de información y la protección de datos en este sector y en los sistemas de información utilizados por estas organizaciones.

\section{Seguridad de información}

Seguridad de la información se encarga de asegurar la confidencialidad, integridad y disponibilidad de la información. Establece a la información como un activo importante de una organización que debe ser protegido, esta área contiene dentro a protección de datos por lo que es un tema importante en considerarse al realizar la investigación para el proyecto. 


\section{Modelos de madurez relacionados a seguridad de información y protección de datos}

\section{Information Governance}

Se presenta como crear un modelo de madurez para el Gobierno de Información basado en documentos de referencia existentes y en métodos de desarrollo de modelos de madurez existentes, luego este modelo es evaluado y se presentan los resultados

\section{Financial Information Security}

El motivo de este trabajo es responder de manera más efectivas a las amenazas al sector financiero. Este estudio construye una evaluación sistemática de seguridad de la información y a la vez una evaluación de un modelo de madurez de seguridad de información.

\section{Cybersecurity Governance}

El modelo de madurez de gobierno de seguridad cibernética tiene como objetivo determinar la madurez general de la seguridad cibernética de una organización. Este se compone de una serie de modelos de madurez de los componentes que, en conjunto, tiene como objetivo determinar el vencimiento global del gobierno de la seguridad cibernética. El resultado final del modelo es un "modelo de madurez de gobierno de seguridad cibernética", que proporcionará un resumen de las evaluaciones de madurez que ha realizado cada uno de los modelos de vencimiento de los componentes. Al hacerlo, la dirección ejecutiva de una organización puede tener un resumen, así como una indicación detallada de su madurez de Gobierno de la Seguridad Cibernética.

\section{Information Security for Middle Size Enterprises}

El problema presentado en este artículo es que los estándares populares contra incidentes de seguridad como (familia ISO 27000x, COBIT, etc.) no se ajustan de la misma forma a la mediana empresa. Aquí se propone un modelo de seguridad de información para medianas empresas (CHOISS) que ayuden a estas empresas a priorizar que riesgos mitigar.

\section{Information Security for all Organizations}

El propósito de este artículo es presentar una evaluación cíclica de un modelo de madurez de seguridad de información que será aplicable a todas las organizaciones. Esto es realizado 
debido a que la falta de un método de evaluación de seguridad puede provocar muchas situaciones de riesgo para las organizaciones

\section{Comparativo de áreas a evaluar}

Luego analizar los artículos presentados se realizó una comparación de las áreas evaluadas por estos modelos de madurez con el fin de obtener aquellos con mayor recurrencia, el resultado se muestra a continuación:

Tabla 6: Comparativo de áreas a evaluar

\begin{tabular}{|c|c|c|c|c|c|c|}
\hline \multirow{2}{*}{ Modelos de Madurez } & \multicolumn{6}{|c|}{ Áreas a evaluar } \\
\hline & Soporte & \begin{tabular}{|c|}
$\begin{array}{c}\text { Tecnología / } \\
\text { Infraestructu } \\
\text { ra }\end{array}$ \\
\end{tabular} & $\begin{array}{l}\text { Gestión / } \\
\text { Personas }\end{array}$ & Procesos & Área Técnica & $\begin{array}{c}\text { Unidades de } \\
\text { negocio }\end{array}$ \\
\hline Information Governance (Proenca, 2016) & & & & & & \\
\hline Financial Information Security (Park, 2014) & & & & & & \\
\hline Cybersecurity Governance (De Bruin, 2016) & & & & & & \\
\hline $\begin{array}{l}\text { Information Security for Middle Size Enterpris } \\
\text { (Minjnhardt, 2016) }\end{array}$ & & & & & & \\
\hline $\begin{array}{l}\text { Information Security for all Organizations } \\
\text { (Rigon, 2014) }\end{array}$ & & & & & & \\
\hline
\end{tabular}

Fuente: Elaboración propia

\section{Normas peruanas relacionadas a la protección de datos}

\section{Circular g-140}

Debido a que el sector objetivo del modelo de madurez de protección de datos personales es el sector micro financiero peruano es necesario considerar esta norma de la Superintendencia de Banca y Seguros relacionada a la gestión de seguridad de información y sus incisos concernientes a la protección de datos.

\section{Ley de protección de datos personales}

Uno de los objetivos principales del modelo de madurez de protección de datos personales es que la organización cumpla satisfactoriamente esta ley para esto se toma en cuenta los diferentes incisos y sobre todo los ocho principios establecidos en la ley. 


\section{Diseño del modelo de madurez}

\section{Modelo de Madurez}

El Modelo de Madurez de Protección de Datos Personales para el Sector Microfinanciero Peruano se representa de manera gráfica en la siguiente Figura. Para iniciar con el análisis, se realiza un cuestionario sustentado con estándares internacionales y normas peruanas, dentro de los dominios determinados. Al finalizar el cuestionario, se realizará el cálculo automático según las respuestas dadas para determinar el nivel en el que la empresa se encuentra.

Figura 5: Modelo de Madurez

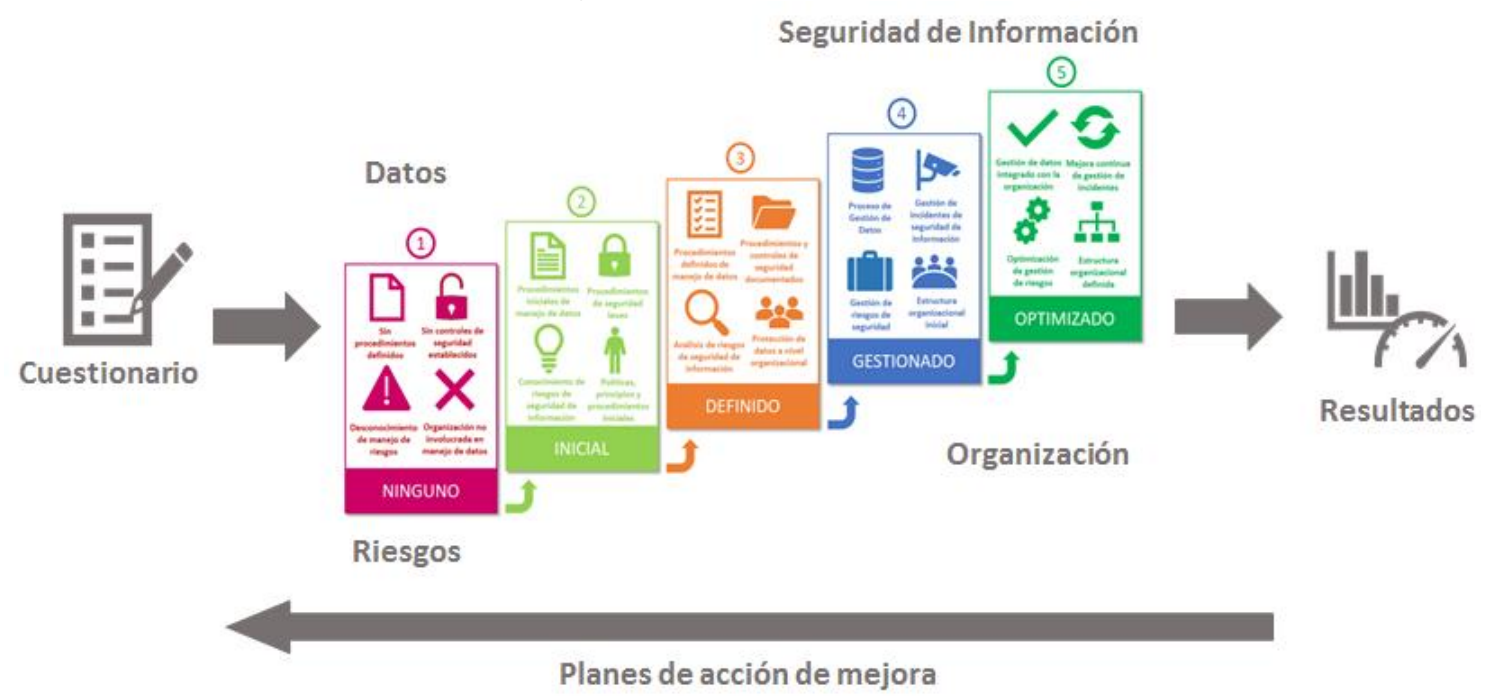

Fuente: Elaboración Propia

\section{Fases de madurez}

Primero se plantean tres fases por las que pueden pasar las organizaciones con el objetivo de alcanzar la madurez en protección de datos personales, estas son:

- Inmadurez: La organización tiene conocimientos y procesos iniciales de protección de datos personales.

- Madurez: La organización posee actividades relacionados a protección de datos definidas y controladas. Conforme el nivel de madurez aumenta, su desempeño en el tema es mayor.

- Excelencia: La organización se encuentra preparada ante cambios y sus actividades son mejoradas continuamente. 


\section{Niveles de madurez}

Los niveles de madurez simbolizan el grado de optimización de los procesos de una organización y sus capacidades respecto a un tema en particular, en nuestro caso la protección de datos personales. Las micro financieras deben escalar estos niveles con el objetivo de mejorar sus capacidades de protección de datos personales. Se definieron cinco niveles:

- Nivel 1 - Ninguno: La organización desconoce total o parcialmente sobre protección de datos personales.

- Nivel 2 - Inicial: Conocen los aspectos de protección de datos y hacen esfuerzos por establecer procesos iniciales de protección y privacidad.

- Nivel 3 - Definido: La organización posee procesos definidos relacionados a protección de datos.

- Nivel 4 - Gestionado: Los procesos relacionados a protección de datos de la organización son gestionados de tal manera que existen actividades de identificación, análisis y evaluación.

- Nivel 5 - Optimizado: La organización ha alcanzado un nivel de excelencia en sus actividades, evalúan periódicamente sus procesos en busca de mejorar los mismos y eliminar errores, alcanzando así altos niveles de efectividad.

La relación entre las fases y los niveles de madurez se muestra en la siguiente tabla:

Tabla 7 : Fases y niveles de madurez

\begin{tabular}{|l|c|c|c|c|}
\hline \multicolumn{2}{|c|}{ Inmadure z } & \multicolumn{2}{c|}{ Madurez } & Excelencia \\
\hline Nivel 1 & Nivel 2 & Nivel 3 & Nivel 4 & Nivel 5 \\
Ninguno & Inicial & Definido & Gestionado & Optimizado \\
\hline
\end{tabular}

Fuente: Elaboración Propia

\section{Dominios}

El modelo de madurez de protección de datos personales se divide en cuatro dominios, que representan los diferentes puntos de vista de protección de datos en una organización. Los dominios son: 


\section{Datos}

Dominio en el que se considera el ciclo de vida de datos, además de la seguridad y la disponibilidad de estos.

\section{Seguridad de información}

Abarca las medidas preventivas y reactivas de la organización que permiten proteger la información

\section{Riesgos}

Este dominio involucra las actividades necesarias para la gestión de riesgos como: definición de contexto, identificación, análisis, evaluación, tratamiento y monitoreo.

\section{Organización}

Dominio que evalúa el involucramiento y el conocimiento de la organización y las personas de esta en relación con la protección de datos.

\section{Referencias}

Para la selección de los criterios se utilizaron como base los siguientes estándares y regulaciones, tomando en cuenta aquellos puntos relacionados a la protección de datos personales.

\section{Estándares}

- ISO/IEC 27002: Controles para la implementación de un Sistema de Seguridad de Información (SGSI)

- ISO/IEC 29100: Framework de Privacidad del que se consideran los once principios de privacidad que son aplicados a factores legales, contractuales, comerciales, etc.

- ISO/TR 17944: Framework de Seguridad en Sistemas Financieros del cual se tomó las áreas de estandarización relacionadas a protección de datos que son pertinentes para el sector micro financiero peruano.

\section{Regulaciones}

- Ley de Protección de Datos Personales $N^{\circ}$ 29733: Uno de los objetivos principales del modelo de madurez de protección de datos personales es que la organización cumpla satisfactoriamente esta ley para esto se toman en cuenta los diferentes incisos y sobre 
todo los ocho principios establecidos en la ley.

- Circular $\mathrm{N}^{\circ}$ g-140: Debido a que el sector objetivo del MMPDP es el sector micro financiero peruano es necesario considerar esta norma de la SBS relacionada a la gestión de seguridad de información y sus incisos concernientes a la protección de datos.

\section{Criterios}

Los criterios fueron seleccionados a partir de la recurrencia de estos en diversos modelos de madurez relacionados a la seguridad de información y protección de datos. Estos a su vez están vinculados con los elementos de las referencias mencionadas en la sección anterior, los criterios agrupados por dominio son los siguientes:

\section{Datos}

- Recolección: Actividades que abarcan la recolección de datos personales mediante cualquier medio (oral, escrito, online, etc.)

- Tratamiento: Almacenamiento y procesado de los datos recolectados

- Transferencia: Establece la necesidad de comunicar y solicitar permiso para transferir datos personales a empresas del mismo grupo corporativo, a empresas terceras y a empresas fueras del país asegurando la protección de los mismos en todos los casos.

- Eliminación: Se asegura que solo las personas autorizadas puedan eliminar datos en caso se cumpla el plazo de tratamiento de estos, plazo que debe ser informado al titular de datos.

- Identificación y clasificación: Identificar a los datos como activos de la organización y darles prioridad de acuerdo con las características de los datos.

- Integridad: Mantener actualizados los datos, verificar su autenticidad y corregir en caso de errores a pedido del titular de datos.

\section{Seguridad de información}

- Incidentes: Manejo de incidentes de seguridad de información con actividades preventivas, reactivas y correctivas ante estos.

- Identificación del titular de datos: Existen requisitos definidos para asegurar la identificación del titular de datos para hacer uso de los derechos sobre sus datos personales. 
- Seguridad lógica: Seguridad relacionada a la asignación y baja de accesos a los sistemas de información que manejan datos personales.

- Seguridad física: Seguridad relacionada al acceso físico a los centros de almacenamiento, así como también la seguridad del hardware que soporta las bases de datos.

- No repudio: Actividades que permiten que, en este caso, el titular de datos no pueda declarar como falsa la autenticidad de alguna acción realizada por el mismo.

- Procedimientos de respaldo: Existencia y seguimiento de procedimientos de respaldo de información.

\section{Riesgos}

- Identificación de vulnerabilidades: Se identifican los puntos débiles de seguridad de información tanto a nivel tecnológico como organizacional.

- Identificación de amenazas: Se identifican las fuentes que pueden aprovechar las vulnerabilidades para obtener algún beneficio económico y perjudicar a la organización.

- Determinación de probabilidad: Definir cuantitativamente la probabilidad de riesgos y definir acciones de respuesta.

- Análisis de impacto: Análisis del impacto económico, reputacional y operacional

- Implementación de controles: Controles que permitan mitigar los riesgos identificados, disminuyendo la probabilidad de ocurrencia y minimizando el impacto de estos.

\section{Organización}

- Capacitación del personal: El personal involucrado con el manejo de datos personales está debidamente capacitados para hacer uso de estos y conocen y cumplen los principios y políticas definidas por la organización

- Asignación de responsabilidades: Existe una segregación de funciones definida.

- Comunicación externa: Comunicación periódica e información disponible sobre los derechos del titular de datos y la seguridad de información con la que se cuenta en la organización

- Políticas y principios: Se definen políticas y principios de protección de datos personales y se vela por cumplir las mismas en toda la organización

- Selección del personal: Se toma con alta importancia la integridad y confidencialidad de las personas que tomarán cargos relacionados con el manejo de datos personales. 


\section{Preguntas de evaluación}

La relación de los criterios mencionados con los estándares utilizados en el presente trabajo se muestra en la siguiente tabla:

Tabla 8: Alineación a estándares y regulaciones

\begin{tabular}{|c|c|c|c|c|c|c|c|}
\hline Código & Criterios & 29733 & 27002 & G140 & ARCO & 29100 & 17944 \\
\hline D1 & Recolección de datos & $\mathrm{P} 1 ; \mathrm{P} 2 ; \mathrm{P} 3 ; \mathrm{P} 4$ & - & - & $\mathrm{AO}$ & $\mathrm{P} 1 ; \mathrm{P} 2 ; \mathrm{P} 3$ & - \\
\hline D2 & Tratamiento de datos & $\mathrm{P} 3 ; \mathrm{P} 4 ; \mathrm{P} 7$ & - & - & AR & P5;P8 & - \\
\hline D3 & Transferencia de datos & $\mathrm{P} 3 ; \mathrm{P} 4 ; \mathrm{P} 7$ & A. 15.1 & $\begin{array}{c}5.5 \mathrm{e} ; 6 \\
7\end{array}$ & $\mathrm{ARO}$ & P5;P11 & 8.40 \\
\hline D4 & Transferencia de datos & $\mathrm{P} 3 ; \mathrm{P} 4 ; \mathrm{P} 7$ & A. 15.1 & $\begin{array}{c}5.5 \mathrm{e} ; 6 \\
7 \mathrm{a}\end{array}$ & ARO & $\mathrm{P} 5 ; \mathrm{P} 11$ & 8.40 \\
\hline D5 & Eliminación de datos & P7 & - & - & $\mathrm{CO}$ & $\mathrm{P} 4$ & - \\
\hline D6 & Eliminación de datos & $\mathrm{P} 7$ & - & - & $\mathrm{AC}$ & - & - \\
\hline D7 & $\begin{array}{l}\text { Identificación y } \\
\text { clasificación de datos }\end{array}$ & P5 & A.8.2.1 & 5.40 & - & P6 & - \\
\hline D8 & Integridad de datos & P5 & - & - & - & P6 & - \\
\hline $\mathrm{O} 1$ & Capacitación del personal & - & - & $4 c$ & - & - & - \\
\hline $\mathrm{O} 2$ & $\begin{array}{l}\text { Asignación de } \\
\text { responsabilidades }\end{array}$ & P8 & A.6.1.1 & $5.5 \mathrm{c}$ & A & P9 & - \\
\hline $\mathrm{O} 3$ & Comunicación externa & $\mathrm{P} 7$ & - & - & A & P7 & - \\
\hline $\mathrm{O} 4$ & $\begin{array}{c}\text { Políticas y principios } \\
\text { organizacionales }\end{array}$ & - & A.5.1.1 & $3 c ; 4 a$ & - & P9 & - \\
\hline $\mathrm{O5}$ & Selección de personal & - & A.7.1.1 & 5.20 & - & - & - \\
\hline $\mathrm{R} 1$ & $\begin{array}{l}\text { Determinación de } \\
\text { probabilidad }\end{array}$ & - & A.12.7.1 & $\begin{array}{c}3 \mathrm{~b} ; 4 \mathrm{~b} \\
5.8 \mathrm{a}\end{array}$ & - & P10 & - \\
\hline $\mathrm{R} 2$ & Anális is de impacto & - & A.12.7.1 & $3 b$ & - & - & - \\
\hline R3 & $\begin{array}{l}\text { Implementación de } \\
\text { controles }\end{array}$ & - & A. 12.7 .1 & $3 b ; 10$ & - & - & - \\
\hline $\mathrm{R} 4$ & $\begin{array}{l}\text { Identificación de } \\
\text { vulnerabilidades }\end{array}$ & - & - & $\begin{array}{l}5.6 f \\
5.8 \mathrm{a}\end{array}$ & - & P10 & - \\
\hline R5 & Identificación de amenazas & - & - & - & - & $\mathrm{P} 10$ & - \\
\hline $\mathrm{S} 1$ & $\begin{array}{c}\text { Incidentes de seguridad de } \\
\text { información }\end{array}$ & P6;P8 & A.16.1 & $4 \mathrm{~d} ; 5.8$ & - & P10 & 6.50 \\
\hline $\mathrm{S} 2$ & $\begin{array}{c}\begin{array}{c}\text { Identificación del titular de } \\
\text { datos }\end{array} \\
\end{array}$ & P1;P6;P8 & - & - & - & $\mathrm{P} 4 ; \mathrm{P} 10 ; \mathrm{P} 11$ & $\begin{array}{l}2.1 \\
2.3\end{array}$ \\
\hline S3 & Seguridad lógica & P6;P8 & A.9.2 & 5.10 & - & $\mathrm{P} 10$ & 2.10 \\
\hline S4 & Seguridad física & P6;P8 & A.11.1.2 & 5.30 & - & P10 & 2.10 \\
\hline S5 & No repudio & - & - & - & - & P10 & $\begin{array}{l}5.3 \\
5.4\end{array}$ \\
\hline S6 & $\begin{array}{l}\text { Procedimientos de } \\
\text { respaldo }\end{array}$ & P8 & A.12.3.1 & 5.70 & - & P10 & 6.10 \\
\hline
\end{tabular}

Fuente: Elaboración Propia 
Las preguntas presentan una definición del criterio de evaluación y presenta una variedad de opciones enfocadas al nivel de las capacidades de la organización en relación con tal criterio. El detalle de cada pregunta se muestra a continuación:

- Recolección de datos (D1): La recolección de datos es el acto de solicitar datos personales tales como (nombres completos, información de contacto, etc.). Este acto puede realizarse mediante formularios online, de manera presencial oral y/o escrita, vía telefónica, etc.

- La recolección de datos se realiza sin consentimiento del titular y sin especificar la finalidad del proceso

- Se solicita el consentimiento del titular, más no se indica claramente la finalidad del proceso

- Se comunica la finalidad de la recolección y se solicita consentimiento a través de cualquier vía en la que se realizará dicho proceso.

- Se comunica de manera clara la finalidad de la recolección y se solicita consentimiento a través de cualquier vía en la que se realizará dicho proceso.

- El procedimiento de recolección de datos se encuentra documentado e incluye la solicitud de consentimiento y el propósito de la recolección sea cual fuere el medio de recolección

- Tratamiento de datos (D2): Cualquier operación o procedimiento técnico que permita la extracción, consulta, registro, organización, almacenamiento, modificación, bloqueo, suspensión, difusión o cualquier otra forma de procesamiento de los datos personales

- Los datos personales se utilizan para procedimientos fuera de la finalidad que se establece al momento de la recolección

- Existen procedimientos definidos sobre el alcance del tratamiento de datos de acuerdo con la finalidad de su recolección

- Existen procedimientos definidos y documentados sobre el alcance del tratamiento de datos y son realizados solo por personal autorizado y capacitado

- Transferencia de datos (D3): Transferencia del total o parte del banco de datos personales a terceros con una finalidad establecida dentro del ámbito del negocio

- Las transferencias de datos se realizan libremente sin considerar el riesgo que esto conlleva 
- Se tiene el consentimiento del titular para el proceso de transferencia

- Se tiene el consentimiento del titular y se le comunica la finalidad por la que sus datos están siendo transferidos a empresas del mismo grupo o a proveedores externos

- Transferencia de datos (D4): El flujo transfronterizo de datos personales consiste en enviar datos fuera del país de origen de estos. El destinatario debe contar con niveles de protección adecuados a la ley 29733. No aplica para casos de transferencias bancarias esto incluye solo datos relacionados a la transacción.

○ Los datos se transfieren libremente hacia el extranjero

- Se solicita el consentimiento del titular, esto puede ser al momento de la recolección o al momento de la transferencia.

- Además del consentimiento se garantiza que el destinatario cuenta con un nivel de protección adecuado a la ley. El titular del banco de datos es el responsable por algún incumplimiento.

- Eliminación de datos (D5): La eliminación de datos puede realizarse a pedido del titular en caso de omisión, error o falsedad. Además, puede pedir la cancelación de estos si los datos no son utilizados para la finalidad presentada al momento de la recolección

○ No se responde a solicitudes fundadas de eliminación

- Existe un procedimiento de atención a solicitudes fundadas de eliminación de datos

- La organización comunica y solicita consentimiento al titular en caso requiera utilizar los datos para una finalidad diferente a la presentada al momento de recolección.

- Se realizan procedimientos periódicos de actualización de datos personales

- Eliminación de datos (D6): Los datos recolectados tienen un plazo de vencimiento presentando al momento de la recolección. En el caso del sector financiero, la organización está obligada por ley a retener los datos por 10 años, en caso sean necesarios para investigaciones hechas por el estado.

○ No se establece un plazo de vencimiento del tratamiento de datos

- Se establece un plazo de vencimiento según la finalidad del proceso y se les comunica además el período de retención por ley 
- Además del plazo de vencimiento y el período de retención, los datos personales solo pueden ser eliminados por personas autorizadas en la organización

- Identificación y clasificación de datos personales (D7): Los datos deben ser identificados como activos de la organización y estos deben ser organizados y clasificados de acuerdo con el riesgo que existen en la organización

○ No existe identificación ni clasificación de datos en la organización

- Se realiza un inventario de datos

○ Los datos son clasificados de acuerdo con el nivel de riesgo que estos suponen para la empresa

- Integridad de datos (D8): Se debe verificar que los datos personales que posee la organización en su banco de datos sean correctos, reales y, en caso sea necesario, actualizados con el objetivo de garantizar la calidad de estos.

- No se verifican la fuente de los datos recolectados ni se realizan actualizaciones o correcciones de estos.

- Se realiza verificación de la autenticidad de los datos luego de la recolección de estos

- Además de verificar la autenticidad de los datos, se realizan solicitudes de actualizaciones periódicas a los titulares para los datos que se consideren necesarios actualizar

- Capacitación del personal (O1): Concientización y capacitación sobre procedimientos para la protección de datos personales dentro de la organización

- No existen procedimientos de concientización de protección de datos en la organización

○ Existen procedimientos definidos sobre la concientización de protección de datos, pero estos se cumplen parcialmente

- Solo el personal del área encargada de manejar el banco de datos se encuentra concientizada sobre la protección de datos

- Asignación de responsabilidades (O2): En el caso del sector micro financiero persona jurídica es la responsable de los datos personales recopilados. Sin embargo, dentro de la 
organización es necesario asignar responsabilidades sobre el banco de datos personales y el manejo de los mismos.

○ No existen responsabilidades definidas

- Existe asignada una persona responsable del banco de datos personales

- Existe un oficial de seguridad de la información al cual le reportan las personas que manejan los bancos de datos personales

- Comunicación externa (O3): Se comunica de manera clara el manejo de los datos personales hacia los titulares de los datos. El manejo de estos datos incluye responsables, finalidad, almacenamiento, métodos de consulta y actualización, transferencia y plazo del tratamiento

- No se comunica a los clientes los derechos que tienen en relación con sus datos personales que fueron entregados a la organización

- Existe información sobre los derechos del titular en las oficinas de la organización

- Existe información sobre los derechos del titular tanto en ambientes físicos de la organización como por medios electrónicos (correo, página web, etc.)

- Políticas y principios organizacionales (O4): La organización posee políticas y principios que están de acuerdo con la protección de datos personales tales como, políticas de privacidad, políticas de cumplimento, principios éticos a las cuales se les exige cumplimiento en toda la organización

- La organización no define políticas o principios acordes a la protección de datos

- Se definen políticas y principios acordes a la protección de datos, pero no hay métodos de aseguramiento del cumplimiento de estos

- Se verifica constantemente el cumplimiento de las políticas y principios de la organización

- Selección de personal (O5): Se verifican los antecedentes de los potenciales empleados de acuerdo con las leyes y regulaciones relevantes tanto para sector financiero como para la protección de datos personales

- Se verifican solo los antecedentes relacionados a los requisitos del negocio

- Se verifican los antecedentes de acuerdo con las legislaciones laborales y las 
regulaciones normativas vigentes.

- Determinación de probabilidad (R1): El resultado de un análisis de controles es utilizado para reforzar la determinación de que una amenaza específica pueda explotar satisfactoriamente una vulnerabilidad del sistema u organización

○ No existen controles establecidos

- Existen controles establecidos, pero no se realiza un análisis de estos con el objetivo de mejorar la determinación de probabilidad

- Se utiliza un checklist o cuestionario para analizar los controles establecidos que protegen los sistemas de la organización

- Análisis de impacto (R2): Se determina la probabilidad de que una amenaza explote una vulnerabilidad. La probabilidad es descrita en términos cuantitativos bajos, moderados y altos.

- No existe una matriz de probabilidades definida

- Se clasifica la probabilidad de que un incidente suceda según un análisis de amenazas y vulnerabilidades del sistema de seguridad de información

- Considerando el análisis de amenazas y vulnerabilidades se establece una matriz de probabilidad de riesgos en términos cuantitativos

- Implementación de controles (R3): Se realiza un análisis de impacto para determinar cómo afecta a la organización de manera económica, reputacional u operativa. Para el caso de datos personales se consideran las sanciones y demandas legales

- No se considera el impacto que tiene un riesgo de seguridad en la organización

- Se conocen las sanciones (leves, moderadas y graves) que aplican por incumplimiento de leyes regulatorias. Sin embargo, no se existe un análisis del impacto de estas sanciones en la empresa

- Se realiza un análisis de impacto con el objetivo de conocer cómo afectan las sanciones a la tolerancia de riesgo de la organización

- Identificación de vulnerabilidades (R4): Las vulnerabilidades son debilidades o fallas en los procedimientos, diseño, implementación o controles internos de la seguridad de un sistema que pueden ser activados accidentalmente o de manera intencional y resultan en una violación a la seguridad de información 
- No existe un listado de vulnerabilidades de seguridad de información

- Existe un listado de vulnerabilidades de seguridad de información

○ Existe un listado de vulnerabilidades de seguridad de información categorizado por: fuentes técnicas, humanas y de infraestructura

- Identificación de amenazas (R5): Identificar las fuentes de amenazas que tienen el potencial de explotar debilidades del sistema o de la organización

- No existe un listado de potenciales fuentes de amenazas

- Existe un listado de potenciales fuentes de amenazas

○ Existe un listado de potenciales fuentes de amenazas categorizado en: amenazas naturales, amenazas humanas y amenazas del entorno

- Incidentes de seguridad de información (S1): La organización tiene capacidad de respuesta ante un incidente de seguridad de información, identificándolos, minimizando la pérdida y destrucción, identificando debilidades y recuperando información y operaciones de manera rápida

- No existe una respuesta definida frente a un incidente de seguridad de información

○ Los incidentes están identificados y clasificados

- Existen procedimientos formales para el reporte y respuesta a los incidentes relacionados a vulnerabilidad de seguridad de información

- Identificación del titular de datos (S2): Para ejercer sus derechos como titular de los datos personales este debe identificarse debidamente, estos derechos son adjudicados únicamente al titular y no son transferibles

- La información es brindada a personas que acreditan efectivamente conexión al titular de datos

○ La ejecución de los derechos es realizada solo por el titular de datos identificado con su documento nacional de identidad vigente

- Para consultas electrónicas la identificación se asegura mediante datos de la tarjeta de crédito o débito otorgada por la institución y/o PIN (Personal Identification Numbers)

- Seguridad lógica (S3): Control de acceso a la información proveniente del banco de datos personales en la organización. Desde la opción 2 las respuestas son acumulativas. 
- No existen controles o restricciones para acceder a la información dentro de la organización

○ El acceso a los aplicativos y los datos personales de estos es otorgado según las funciones que realizan

- Existen procedimientos de baja y alta a los usuarios con acceso a aplicativos que utilicen información del banco de datos personales

- Seguridad física (S4): Involucra la seguridad del hardware que aloja el banco de datos personales, el entorno y la ubicación geográfica

- No existen controles para evitar el acceso físico no autorizado

- Existen controles definidos para evitar el acceso físico no autorizado

- Existen controles definidos para evitar el acceso físico no autorizado y las bases de datos están alojados en ambientes controlados

- No repudio (S5): Métodos para evitar que el titular de datos niegue haber realizado una operación a través de un medio electrónico

○ No existen métodos de no repudio

- Se exigen firmas digitales en comunicaciones electrónicas para validar la autenticidad del titular de datos

- Además de las firmas digitales se solicita un sello de tiempo en las comunicaciones electrónicas

- Procedimientos de respaldo (S6): Existen procedimientos de respaldo de información como parte de la estrategia de recuperación

○ No existen procedimientos de respaldo

- Se realizan copias de seguridad de los bancos de datos personales

- La información de respaldo se encuentra en una ubicación alejada del centro principal de datos

\section{Cálculo de los resultados}

Para realizar el cálculo de los resultados de la evaluación, se debe considerar los principios de la ley de protección de datos personales los cuales son:

- Legalidad (P1): El tratamiento de los datos personales se hace conforme a lo establecido 
en la ley de protección de datos personales. Se prohíbe la recopilación de los datos personales por medios ilícitos.

- Consentimiento o Autorización (P2): Para realizar el tratamiento de los datos personales se debe contar con el consentimiento o la autorización de la persona, titular de los datos personales.

- Finalidad (P3): Los datos personales no deben ser tratados para una finalidad distinta a la establecida al momento de su recopilación.

- Proporcionalidad (P4): Todo tratamiento de datos personales debe ser apropiado a la finalidad para la que éstos hubiesen sido recopilados, usando la información que sea imprescindible y suficiente, sin excesos.

- Calidad (P5): Los datos personales que se tratan deben ser veraces, exactos y adecuados.

- Seguridad (P6): El titular del banco de datos personales y el encargado del tratamiento deben adoptar las medidas necesarias para garantizar la seguridad y confidencialidad de los datos personales que administran.

- Disposición de recurso (P7): El titular de datos personales debe contar con mecanismos que le permitan reclamar y hacer valer sus derechos, cuando estos sean vulnerados por el tratamiento de sus datos personales.

- Nivel de protección adecuado (P8): Garantizar los niveles de protección adecuados cuando los datos personales sean transferidos fuera de los límites territoriales peruanos.

La asignación de pesos a cada pregunta se realizó en base a la importancia de cada principio de la ley de protección de datos personales, esta priorización fue consultada un experto consultor que participó en el desarrollo de la directiva de seguridad para ley 29733. La asignación se muestra en la siguiente tabla:

Tabla 9: Calificación de los criterios de evaluación

\begin{tabular}{|c|c|c|c|c|c|}
\hline Dominio & Criterios & Peso & Min & Max & LPDP \\
\hline \multirow{4}{*}{ Datos } & Recolección de datos & 4 & 0.00 & 4.00 & P1;P2;P3;P4 \\
\cline { 2 - 6 } & Tratamiento de datos & 3 & 0.00 & 3.00 & P3;P4;P7 \\
\cline { 2 - 6 } & Transferencia de datos & 3 & 0.00 & 3.00 & P3;P4;P7 \\
\cline { 2 - 6 } & Transferencia de datos & 3 & 0.00 & 3.00 & P3;P4;P7 \\
\cline { 2 - 6 } & Eliminación de datos & 4 & 0.00 & 4.00 & $\mathrm{P} 7$ \\
\cline { 2 - 6 } & Eliminación de datos & 4 & 0.00 & 4.00 & $\mathrm{P} 7$ \\
\cline { 2 - 6 } & Identificación y clasificación de datos & 2 & 0.00 & 2.00 & $\mathrm{P} 5$ \\
\cline { 2 - 6 } & Integridad de datos & 2 & 0.00 & 2.00 & $\mathrm{P} 5$ \\
\hline
\end{tabular}




\begin{tabular}{|c|c|c|c|c|c|}
\multirow{5}{*}{ Organización } & Capacitación del personal & 1 & 0.00 & 1.00 & - \\
\cline { 2 - 6 } & Asignación de responsabilidades & 5 & 0.00 & 5.00 & P8 \\
\cline { 2 - 6 } & Comunicación externa & 4 & 0.00 & 4.00 & P7 \\
\cline { 2 - 6 } & Políticas y principios organizacionales & 1 & 0.00 & 1.00 & - \\
\cline { 2 - 6 } & Selección de personal & 1 & 0.00 & 1.00 & - \\
\hline \multirow{4}{*}{ Riesgos } & Determinación de probabilidad & 1 & 0.00 & 1.00 & - \\
\cline { 2 - 6 } & Análisis de impacto & 1 & 0.00 & 1.00 & - \\
\cline { 2 - 6 } & Implementación de controles & 1 & 0.00 & 1.00 & - \\
\cline { 2 - 6 } & Identificación de vulnerabilidades & 1 & 0.00 & 1.00 & - \\
\cline { 2 - 6 } & Identificación de amenazas & 1 & 0.00 & 1.00 & - \\
\hline \multirow{4}{*}{$\begin{array}{l}\text { Seguridad de } \\
\text { información }\end{array}$} & Incidentes de seguridad de información & 5 & 0.00 & 5.00 & P6;P8 \\
\cline { 2 - 6 } & Identificación del titular de datos & 5 & 0.00 & 5.00 & $\mathrm{P} 1 ; \mathrm{P} 6 ; \mathrm{P} 8$ \\
\cline { 2 - 6 } & Seguridad lógica & 5 & 0.00 & 5.00 & $\mathrm{P} 6 ; \mathrm{P} 8$ \\
\cline { 2 - 6 } & Seguridad física & 5 & 0.00 & 5.00 & $\mathrm{P} 6 ; \mathrm{P} 8$ \\
\cline { 2 - 6 } & Procedimientos de respaldo & 5 & 0.00 & 5.00 & P8 \\
\cline { 2 - 6 } & No repudio & & 0.00 & 1.00 & - \\
\hline
\end{tabular}

Fuente: Elaboración Propia

\section{Elaboración de la herramienta de evaluación}

Para la elaboración de la herramienta de evaluación se optó por utilizar Microsoft Excel ya que es una herramienta ampliamente conocida y fácil de usar para las personas encargadas de realizar la evaluación en nombre de su organización. La herramienta de evaluación consta de las siguientes secciones:

\section{Sección de inicio}

La sección de inicio de la herramienta presenta las instrucciones de uso de la herramienta de manera breve y concisa, como se muestra en la siguiente imagen:

Figura 6: Sección de inicio

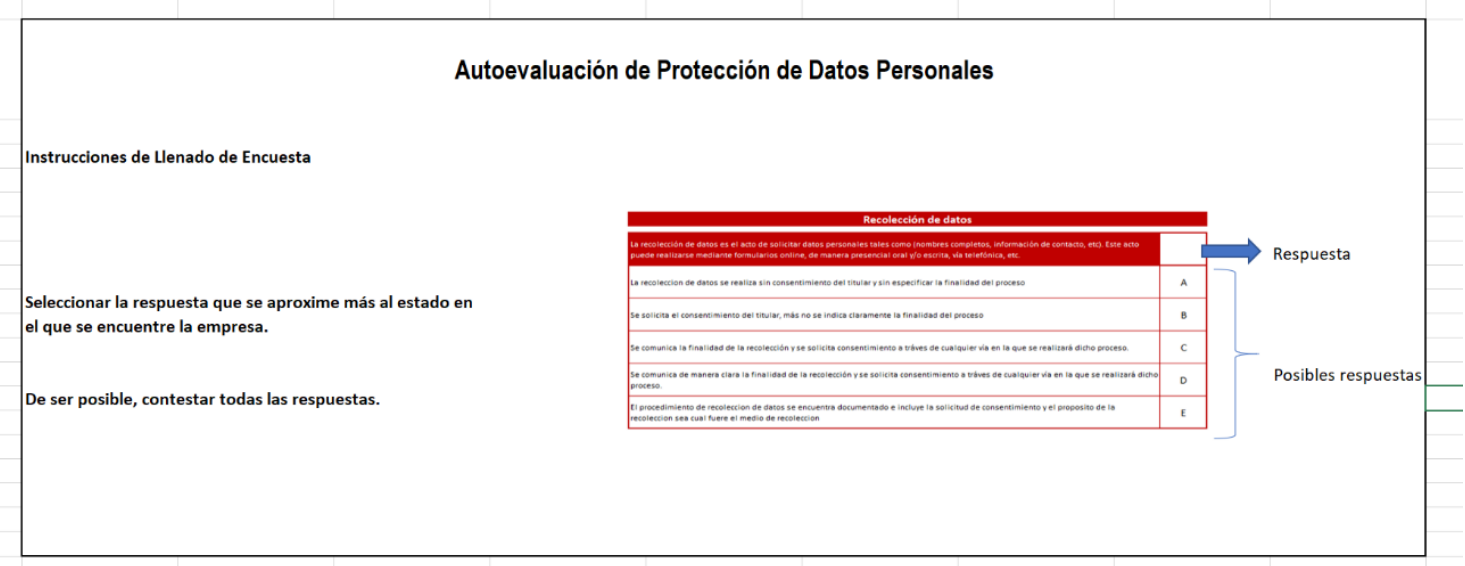

Fuente: Elaboración propia 


\section{Sección de preguntas por dominio}

La siguiente sección se encuentra dividida en cuatro pestañas, una por cada dominio del modelo. Dentro de estas se presentan las preguntas de cada dominio con sus respectivas opciones y el porcentaje completado de las mismas.

Figura 7: Sección de preguntas 1
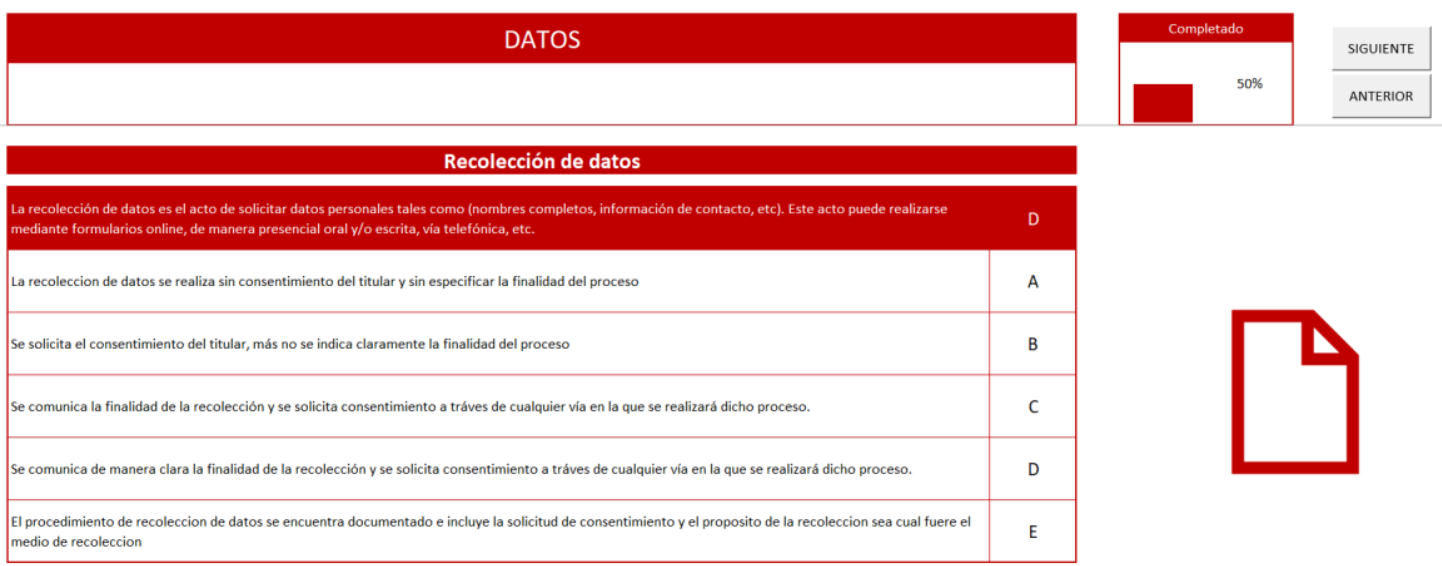

Fuente: Elaboración propia

Figura 8: Sección de preguntas 2
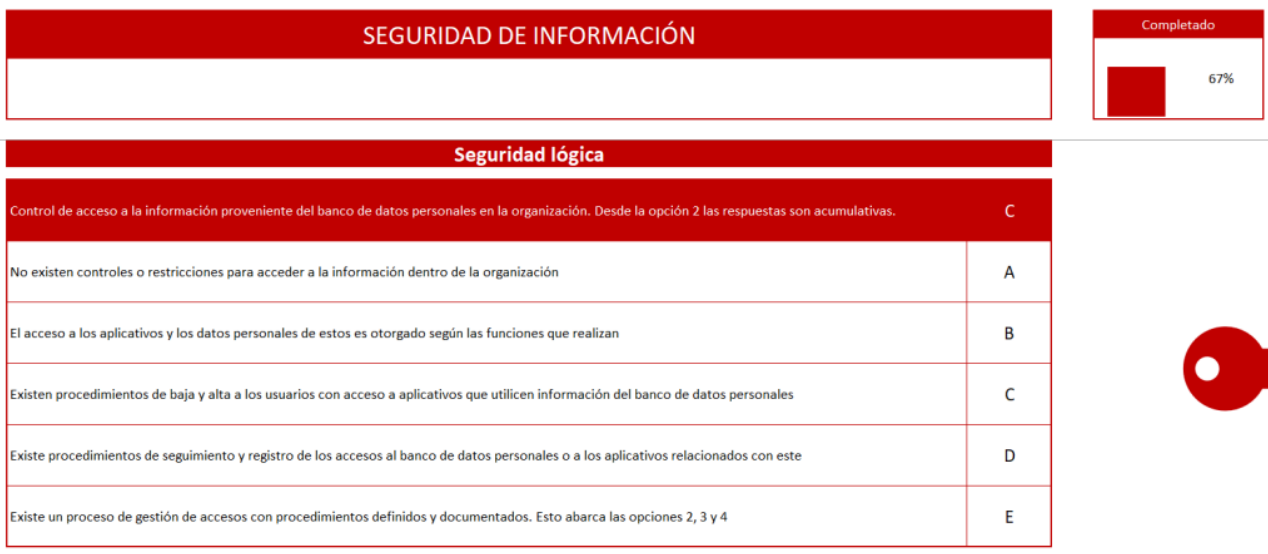

\section{.}

(1)

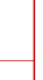

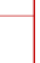

Fuente: Elaboración propia 


\section{Sección de resultados}

Una vez completadas todas las preguntas de la evaluación se muestra la pantalla de resultados la cual contiene el resultado general y los resultados por cada dominio del modelo, los cuales varían de la siguiente manera:

- $0 \%-20 \%$ : Ninguno

- $21 \%-40 \%$ : Inicial

- $41 \%$ - 60\%: Definido

- $61 \%-80 \%$ : Gestionado

- $81 \%-100 \%$ : Optimizado

Figura 9: Sección de resultados

\begin{tabular}{|c|c|c|}
\hline \multicolumn{2}{|c|}{$31 \%$} & INICIAL \\
\hline GENERAL & $24 \%$ & INICIAL \\
\hline DATOS & GESTIONADO \\
\hline ORGANIZACIÓN & $60 \%$ & INICIAL \\
\hline RIESGOS & $33 \%$ & INICIAL \\
\hline $\begin{array}{c}\text { SEGURIDAD DEE } \\
\text { INFORMACIÓN }\end{array}$ & $24 \%$ & \\
\hline
\end{tabular}

Fuente: Elaboración propia 


\section{Capítulo 6: Resultados del Proyecto}

En este capítulo se realiza un análisis de los resultados obtenidos del proyecto, el cual se divide en 2 partes, la primera basada en el juicio de expertos y la segunda es un caso de estudio, tomando como muestra la evaluación a 5 microfinancieras. 


\section{Juicio de expertos}

\section{Expertos}

Para la validación de nuestro proyecto, se contó con tres expertos con experiencia en el sector objetivo (micro financiero), las normas regulatorias del sector financiero y sobre protección de datos personales.

\section{Carlos Horna Vallejos}

Director ejecutivo de GTDI, consultora de Tecnología de información, participó como un consultor del desarrollo de la directiva de seguridad para ley de protección de datos personales. Además ha trabajado como consultor de seguridad de información para diferentes empresas nacionales.

\section{Lucero Valderrama Valderrama}

Actualmente tiene el cargo de Supervisora de Información y Tecnología en la SBS, donde entre sus tareas, supervisa el cumplimiento de regulaciones de seguridad de información en el sector financiero. Además se ha desempeñado previamente como Consultora de Gestión de Riesgos Financieros en KPMG.

\section{Víctor Lujan Cabrera}

Víctor ha sido Trabajador en Riesgos Operacionales en la Financiera Confianza S.A.A., Jefe de Riesgos Operacionales en Compartamos Financiera, Jefe de Riesgos en Caja Trujillo y actualmente tiene el cargo de Jefe de Riesgos en el BBVA Banco Continental.

\section{Presentación del modelo de madurez}

Se coordinó reuniones con los expertos seleccionados con el objetivo de presentar el modelo de madurez y sus diferentes elementos, así como también todas las referencias utilizadas en el diseño del modelo de madurez. 
Figura 10: Modelo de madurez de protección de datos personales

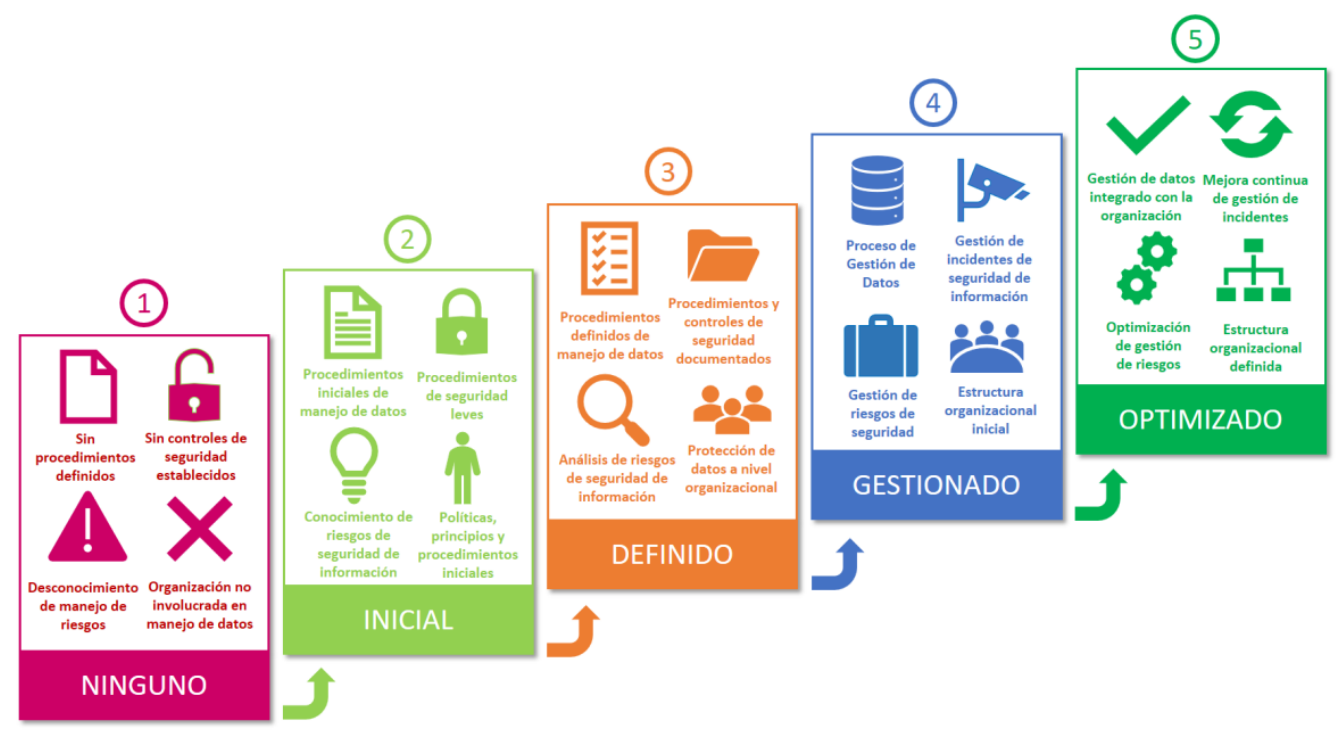

Fuente: Elaboración propia

Además de la presentación del modelo, se realizó junto con ellos una iteración del uso de la herramienta de evaluación con el fin de obtener sus comentarios y recomendaciones sobre la misma.

\section{Resultados del juicio de expertos}

Luego de la presentación, se les solicitó calificar del 1 al 5 a nuestro modelo de madurez, los resultados se muestran a continuación: 
Tabla 10: Resultados de juicio de expertos

\begin{tabular}{|c|c|c|c|c|c|}
\hline Criterio & Carlos Horna & $\begin{array}{c}\text { Lucero } \\
\text { Valderrama }\end{array}$ & Víctor Lujan & \multicolumn{2}{|c|}{ Total } \\
\hline $\begin{array}{c}\text { Orientación al sector } \\
\text { micro financiero }\end{array}$ & 3 & 4 & 5 & 12 & $80 \%$ \\
\hline $\begin{array}{c}\text { Referencias de seguridad } \\
\text { de información }\end{array}$ & 4 & 4 & 4 & 12 & $80 \%$ \\
\hline $\begin{array}{c}\text { Estructura del modelo de } \\
\text { madurez }\end{array}$ & 4 & 4 & 3 & 11 & $73 \%$ \\
\hline $\begin{array}{c}\text { Facilidad de } \\
\text { entendimiento del modelo }\end{array}$ & 5 & 5 & 4 & 14 & $93 \%$ \\
\hline $\begin{array}{c}\text { Facilidad de uso de la } \\
\text { herramienta de evaluación }\end{array}$ & 4 & 5 & 5 & 14 & $93 \%$ \\
\hline $\begin{array}{c}\text { Cumplimiento de normas } \\
\text { regulatorias }\end{array}$ & 3 & 4 & 4 & 11 & $73 \%$ \\
\hline Total & 23 & 26 & 25 & 74 & $82 \%$ \\
\hline
\end{tabular}

Fuente: Elaboración Propia

\section{Caso de estudio}

\section{Micro financieras}

\section{Caja Sipán}

- Caja rural autorizada por la SBS cuyo objetivo es apoyar a pequeñas y medianas empresas, constructores de programa de viviendas, comerciantes e industriales en general.

- Los plazos y tasas de interés se ajustan al flujo de efectivo y al nivel de riesgo del cliente.

La persona que se contactó para realizar la evaluación es el Sr. Raúl Puyen Santos, Oficial de Seguridad de Información de dicha caja.

\section{Crediflorida}

- Cooperativa de origen rural en donde productores cafetaleros organizados, crearon su propia herramienta de desarrollo con la finalidad de acceder al crédito y mejorar las condiciones económica y social de las familias del campo.

La persona de contacto fue Frank Fuentes Valencia, Gerente General de la Cooperativa 


\section{COOPSCB}

- Cooperativa de ahorro y crédito inscrita en el registro de la Superintendencia de Banca y Seguros desde 1994

- Ofrece créditos a microempresas, pequeñas empresas y medianas empresas.

La persona que se contactó para realizar la evaluación es el Sr. Ítalo Reátegui Díaz, Gerente de Riesgos de esta cooperativa.

\section{EDAPROSPO}

- Organización no gubernamental

- Brinda los servicios de créditos individuales y alcancía comunal a comerciantes y pequeños productores que tienen interés por mejorar sus actuales negocios.

La persona que se contactó para realizar la evaluación es el Sr. Jonathan Estrada Estrada, Analista de Finanzas y Recursos Humanas de la cooperativa.

\section{MiBanco}

- Entidad bancaria especializada en atender las necesidades financieras de microempresarios, proporcionando acceso al mercado financiero, convirtiéndose en ese momento en la primera entidad bancaria comercial en el Perú, dedicada exclusivamente al desarrollo de micro finanzas.

La persona de contacto fue Marilyn Pereyra Bernilla, Auditor interno de TI.

\section{Resultados del caso de estudio}

Al consolidar los resultados individuales de cada micro financiera, se identificó la siguiente información

Anális is de resultados:

Resultados por dominio:

- Los dominios de datos y organización presentan un avance aceptable a través de todas las entidades.

- Riesgos es el dominio que demanda un mayor esfuerzo por parte de las organizaciones 
para asegurar una efectiva protección de datos personales. Esto se debe a que las tres primeras empresas no cuentan con un área especializada para relevamiento de riesgos.

- Se identificó que las capacidades en Seguridad de Información mejoran conforme la entidad crece económicamente. Debido a que tienen más recursos para resguardar la información de la empresa.

Tabla 11: Resultados por dominio

\begin{tabular}{|c|c|c|c|c|}
\hline $\begin{array}{c}\text { Micro } \\
\text { Financiera }\end{array}$ & Datos & Organización & Riesgos & $\begin{array}{l}\text { Seguridad de } \\
\text { Información }\end{array}$ \\
\hline \multirow{2}{*}{ EDAPROSPO } & 3 Definido & 1 Ninguno & 1 Ninguno & 2 Inicial \\
\hline & $50 \%$ & $17 \%$ & $17 \%$ & $22 \%$ \\
\hline \multirow{2}{*}{ COOPSCB } & 2 Inicial & 2 Inicial & 1 Ninguno & 2 Inicial \\
\hline & $28 \%$ & $31 \%$ & $10 \%$ & $30 \%$ \\
\hline \multirow{2}{*}{ COOPFLO } & 3 Definido & 4 Gestionado & 1 Ninguno & 2 Inicial \\
\hline & $57 \%$ & $67 \%$ & $10 \%$ & $26 \%$ \\
\hline \multirow{2}{*}{ SIPAN } & 3 Definido & 4 Gestionado & $\begin{array}{c}5 \\
\text { Optimizado }\end{array}$ & $\begin{array}{c}4 \\
\text { Gestionado }\end{array}$ \\
\hline & $57 \%$ & $69 \%$ & $83 \%$ & $66 \%$ \\
\hline \multirow{2}{*}{ MIBANCO } & $\begin{array}{c}5 \\
\text { Optimizado }\end{array}$ & 4 Gestionado & $\begin{array}{c}5 \\
\text { Optimizado }\end{array}$ & $\begin{array}{c}4 \\
\text { Gestionado }\end{array}$ \\
\hline & $69 \%$ & $77 \%$ & $73 \%$ & $77 \%$ \\
\hline
\end{tabular}

Fuente: Elaboración Propia 
Figura 11: Resultados por dominio

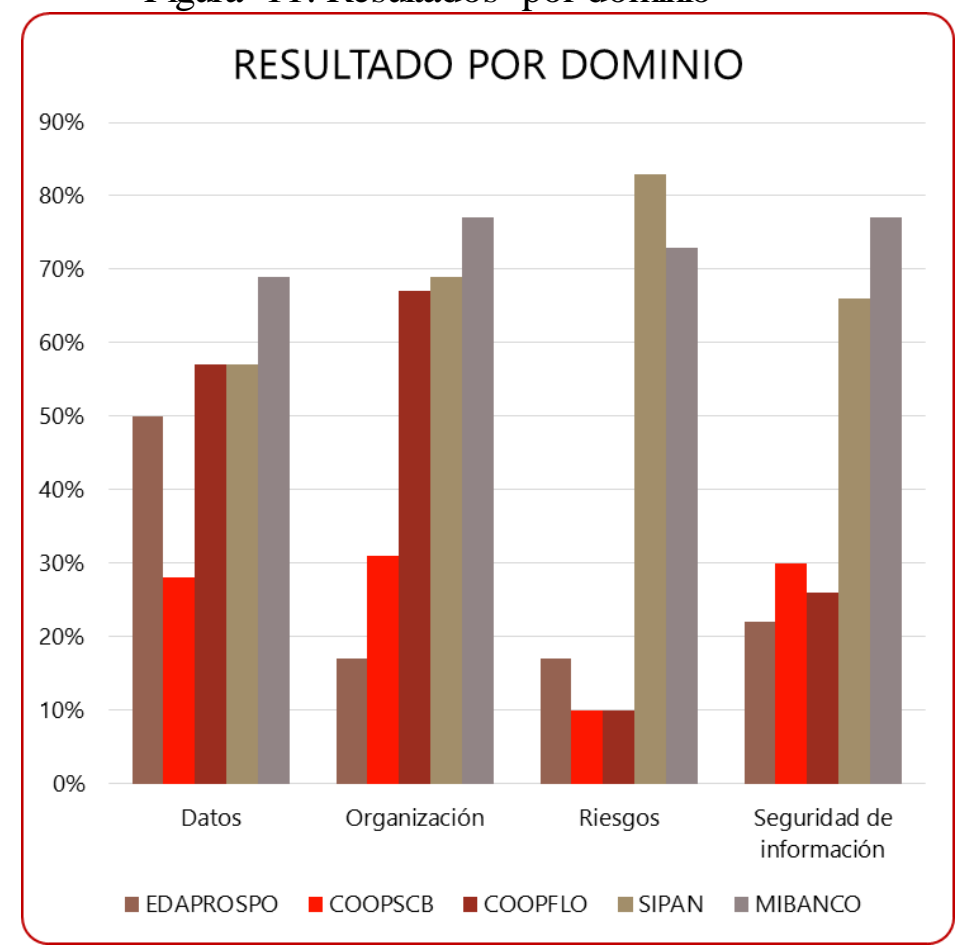

Fuente: Elaboración propia

Resultados generales:

- Los resultados de la muestra evidencian que pese a que ninguna organización se encuentra en un nivel de madurez optimizado, todas se están en un nivel inicial o superior, lo cual nos indica que las micro financieras están conscientes de la importancia de la protección de datos personales y que están haciendo esfuerzos por mejorarla 
Tabla 12: Resultados generales

\begin{tabular}{|c|c|}
\hline Micro financiera & General \\
\hline EDAPROSPO & 2 Inicial \\
\hline COOPSCB & $31 \%$ \\
\hline COOPFLO & 2 Inicial \\
\hline SIPAN & $28 \%$ \\
\hline MIBANCO & 3 Definido \\
\hline & $43 \%$ \\
\hline
\end{tabular}

Fuente: Elaboración Propia

Figura 12: Resultados generales

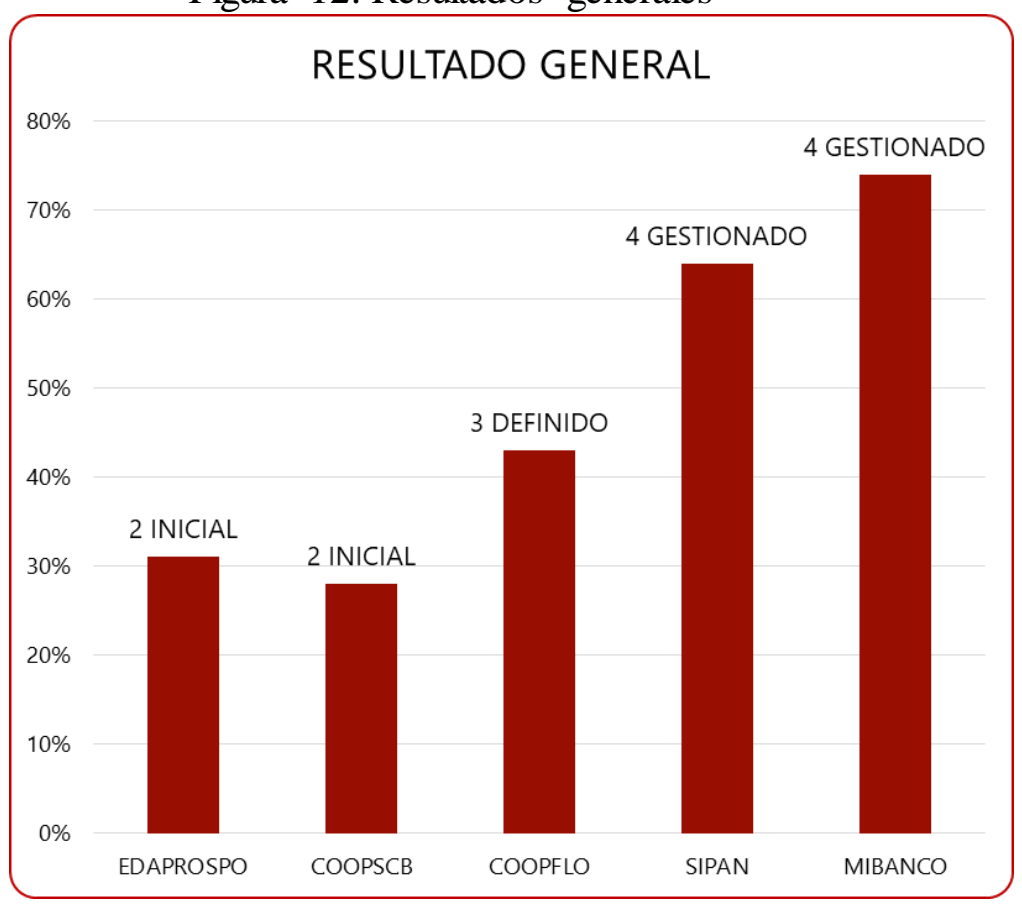

Fuente: Elaboración propia 


\section{Plan de Continuidad}

El presente documento contiene el plan de continuidad para el proyecto Modelo de Madurez de Protección de Datos Personales para el Sector Micro Financiero Peruano - MMPDP. El siguiente contiene un conjunto de tareas que permite asegurar la relevancia del modelo de madurez en el tiempo. Este plan presenta los proyectos a futuro relacionados directamente al trabajo actual, con el objetivo de mejorar la versión existente del modelo de madurez.

\section{Objetivo}

El objetivo del plan de continuidad es establecer los pasos a seguir con la finalidad de mejorar continuamente el modelo de madurez y que se mantenga relevante en el ámbito de la protección de datos personales.

\section{Objetivos específicos}

Los objetivos específicos para el presente plan de continuidad son detallados a continuación:

- Establecer responsabilidades de trabajo

- Trazar la hoja de ruta del proyecto

- Mejorar el modelo de madurez actual

- Garantizar la continuidad del modelo de madurez

\section{Roles de proyecto}

Los roles que se han definido son los siguientes:

\begin{tabular}{|c|c|}
\hline Rol & Responsabilidad \\
\hline Jefe de Proyecto & $\begin{array}{l}\text { - Coordinar reuniones con el asesor del proyecto y con los } \\
\text { expertos para la validación } \\
\text { - Gestionar el repositorio de archivos del proyecto } \\
\text { - Asegurar el cumplimiento de los entregables en las fechas de } \\
\text { - entrega definidas } \\
\text { - Apoyar en la elaboración de los entregables del proyecto }\end{array}$ \\
\hline Jefe de Investigación & $\begin{array}{l}\text { - Realizar la búsqueda de artículos académicos para el proyecto } \\
\text { - Redactar el estado del arte del proyecto } \\
\text { - Apoyar en la elaboración de los entregables del proyecto }\end{array}$ \\
\hline Asesor & $\begin{array}{l}\text { - Orientar en la elección de actividades académicas que ayuden } \\
\text { a la mejora del proyecto } \\
\text { - Supervisar el trabajo de sus asesorados } \\
\text { - Revisar los entregables del proyecto } \\
\text { - Evaluar los objetivos del proyecto }\end{array}$ \\
\hline
\end{tabular}




\section{Resumen de actividades}

Los proyectos y actividades que se realizarán a futuro con el fin de mejorar continuamente el modelo de madurez de protección de datos personales son las siguientes:

Figura 13: Fases del Plan de Continuidad

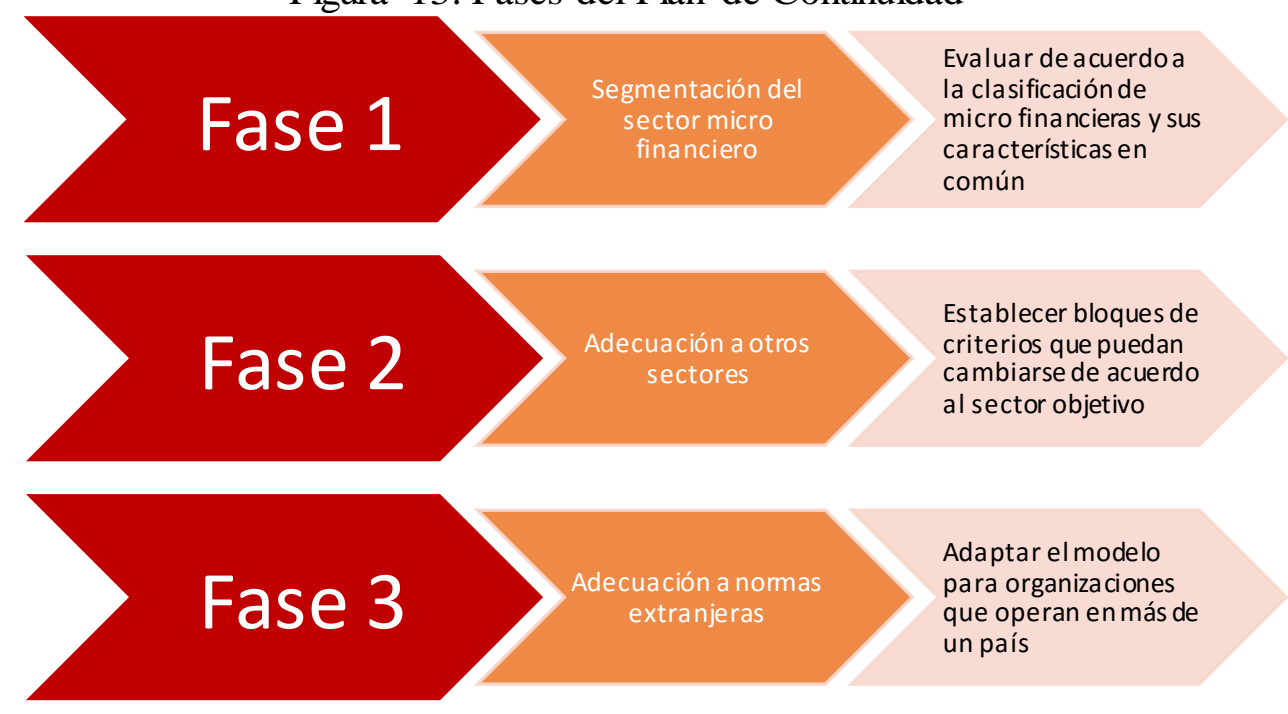

Fuente: Elaboración Propia

\section{Segmentación del sector micro financiero}

La versión actual del modelo de madurez abarca al sector micro financiero en su totalidad, esto comprende cajas municipales, cajas rurales y cooperativas de ahorro. La idea de esta sección es que una micro financiera debe comparar su capacidad en protección de datos personales no solo a nivel general, sino con otras micro financieras de características similares.

Por ejemplo, tenemos dos micro financieras: "A" que tiene presencia a nivel nacional y con una amplia cartera de clientes y "B" que tiene presencia en una ciudad de provincia y cuyos clientes son solo los pobladores de esta ciudad. En este caso la comparación entre "A" y "B" no es muy significativa debido a estas diferencias, por lo que es necesario que se comparen con otras micro financieras de las mismas características. Las siguientes actividades tienen como objetivo solucionar este problema:

\section{Clasificación de micro financieras}

Las actividades por realizar en esta sección son:

- Determinar las características principales que varían entre las diferentes micro financieras.

- Clasificar las micro financieras de acuerdo con las características seleccionadas 
previamente.

Presentar resultados generales y comparativos por segmento

Los resultados de la evaluación son presentados de la siguiente manera:

- Resultado general en el sector micro financiero.

- Resultado comparativo considerando el factor económico.

- Resultado comparativo considerando el factor geográfico.

- Resultado comparativo considerando el factor cartera de clientes.

- Resumen de resultados.

\section{Adecuación a otros sectores}

La protección de datos personales no solo está orientada al sector micro financiero, abarca todos los sectores de negocio. Por esta razón, se plantea que los criterios se agrupen no solo por dominio, sino también por características del sector con la finalidad de que estos conjuntos de criterios funcionen como un "plugin" del modelo de madurez y puedan cambiarse de acuerdo con el sector objetivo del modelo. Las actividades definidas para lograr esta solución son las siguientes:

Analizar los principales sectores de negocio

- Para analizar los principales sectores de negocio en el país se deberá considerar las siguientes características:

- Presencia de mercado

- Ingresos

- Cantidad de clientes

Una vez realizado el análisis se debe determinar las características en común de cada sector, priorizarlas y determinar el impacto de la protección de datos personales en cada sector.

Definir conjunto de criterios relacionados al sector objetivo

Los veintidós criterios definidos en el modelo de madurez se encuentran relacionados a diversos estándares y normas regulatorias, las cuales son:

- Ley de protección de datos personales

- Circular $\mathrm{N}^{\circ} \mathrm{g}-140$

- $\quad$ ISO / IEC 27002 
- $\quad$ ISO / IEC 29100

- $\quad$ ISO / TR 17944

De estas referencias la circular g-140 y la ISO 17944 están relacionadas al sector micro financiero, con el motivo de establecer un conjunto de criterios relacionados a un sector en específico, estas referencias deben ser reemplazadas por unas pertinentes al nuevo sector objetivo.

Establecer prioridad de resultados de acuerdo con el sector objetivo

En el modelo actual se consideran cuatro dominios:

- Datos

- Riesgos

- Seguridad de información

- Organización

Los resultados de la evaluación se presentan de manera general y de manera específica por cada dominio. Estos resultados son calculados otorgando valor a cada criterio según su relación con los ocho principios de la ley de protección de datos personales. Si el sector varía, la prioridad de cada dominio varía de acuerdo con los intereses de ese sector en particular por lo que es necesario adaptar el cálculo del resultado a estos intereses.

Presentar resultados generales, por sector y por segmento de sector

Una vez establecida el nuevo cálculo para la evaluación de las organizaciones es necesario que la herramienta presente los siguientes resultados:

- Resultado general en todos los sectores

- Resultado y comparativo en su sector de negocio

- Resultado y comparativo en cierto segmento del sector objetivo

Por ejemplo, se realiza una evaluación a una universidad, en tal caso se deberían presentar un resultado general, luego un resultado y comparativo solo en el sector educación y finalmente el resultado y comparativo en el segmente de educación superior.

\section{Adaptación a normas extranjeras}

El modelo de madurez trabajado está orientado a que las organizaciones cumplan satisfactoriamente la ley peruana de protección de datos personales, en tal sentido las 
organizaciones del sector objetivo seleccionado pueden operar en diferentes países, lo que crearía la necesidad de que el modelo se adapte a las normas de dichos países.

Para satisfacer esa necesidad se plantean las siguientes actividades:

Investigar principios internacionales de protección de datos

Esta sección tiene como objetivo establecer términos generales sobre protección de datos a nivel mundial:

- Investigar que principios de protección de datos son aceptados a nivel mundial

- Determinar a los países líderes en protección de datos personales

- Determinar a las principales entidades reguladoras de protección de datos personales

Comparar la norma peruana con otros países de América Latina

Seleccionar al menos tres países que cuenten con una legislación sobre protección de datos personales, estudiar sus normas y realizar un análisis comparativo entre estas y la ley local con el objetivo de establecer la dificultad de adaptación del modelo a normas extranjeras.

\section{Protección de Datos Personales en el mundo}

\section{Contexto regional}

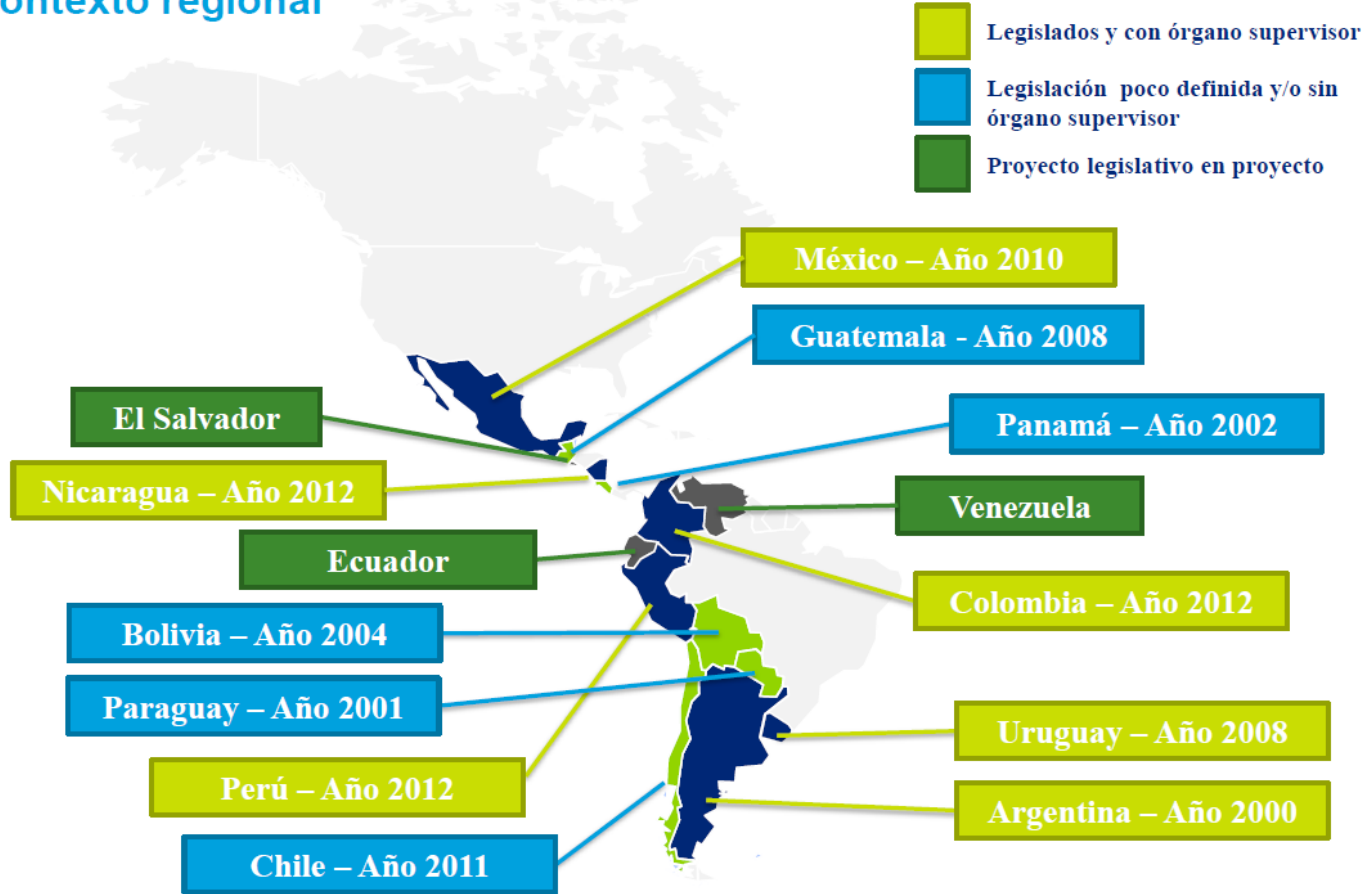

Fuente: Deloitte (2014)

Adaptar criterios para normas extranjeras

Por último, haciendo uso del mismo proceso de "plugins" de la sección dos de este plan de continuidad, se establece un conjunto de criterios relacionado a la norma regulatoria vigente. 
Este conjunto de criterios se cambiará según el país en el que la organización decida realizar la evaluación del modelo de madurez.

\section{Retorno de inversión}

Para calcular el retorno de inversión (ROI) se deben considerar los siguientes factores:

- Sanciones administrativas por infracciones a la ley de protección de datos personales

Los montos de las multas varían en los siguientes intervalos:

Tabla 13: Tasas de Infracciones

\begin{tabular}{|c|c|c|}
\hline Tipo & UIT & Monto en soles \\
\hline Infracción leve & Desde 0.5 - hasta 5 & S/ 2,100.00 - S/ 21,000.00 \\
\hline Infracción grave & Mayor a 5 - hasta 50 & $\mathrm{~S} / 21,000.00-\mathrm{S} / 210,000.00$ \\
\hline Infracción muy grave & Mayor a 50 - hasta 100 & $\mathrm{~S} / 21,000.00-\mathrm{S} / 420,000.00$ \\
\hline
\end{tabular}

Fuente: Elaboración Propia

El detalle de los tipos de infracciones se encuentra en el artículo treinta y ocho de la ley de protección de datos personales. Vale remarcar que en caso de reincidencia en dos (02) infracciones leves la tercera se sanciona como infracción grave y en caso de reincidencia de dos (02) infracciones graves la tercera se sanciona como sanción muy grave.

- Costos de implementación de controles de seguridad de información

Contactamos a uno de los expertos contactados para la validación, el cual estuvo a cargo de la seguridad de la información de tres cajas municipales. Él nos brindó información aproximada de los costos promedio de implementar controles de seguridad de información que equivalen a alrededor del $15 \%$ de los ingresos de una organización.

Para elaborar el cálculo del retorno de inversión se considera el siguiente caso:

Tabla 14: Cálculo del ROI

\begin{tabular}{|c|c|c|c|c|}
\hline Micro financiera & Ingres os & Año 1 & Año 2 & Año 3 \\
\hline CMAC Arequipa & S/ 4,959,900.30 & $15 \%$ & $10 \%$ & $5 \%$ \\
\hline $\begin{array}{c}\text { Inversión en implementación de controles } \\
\text { de seguridad de información }\end{array}$ & $\mathrm{S} / 743,985.05$ & $\mathrm{~S} / 495,990.03$ & $\mathrm{~S} / 247,995.02$ \\
\hline $\begin{array}{c}\text { Ahorro por sanciones } \\
\text { administrativas }\end{array}$ & $\begin{array}{c}\text { Promedio anual } \\
50 \text { UIT }\end{array}$ & $\mathrm{S} / 210,000.00$ & $\mathrm{~S} / 210,000.00$ & $\mathrm{~S} / 210,000.00$ \\
\hline \multicolumn{2}{|c|}{ Retorno de inversión (ROI) } & $\mathbf{- 4 6 \%}$ & $\mathbf{- 1 8 \%}$ & $\mathbf{6 3 \%}$ \\
\hline
\end{tabular}

Fuente: Elaboración Propia 
- Caja Arequipa con ingresos de cerca de cinco millones de soles según la SBS.

- Costos de implementación en controles de seguridad de información de $15 \%$ para el primer año y disminuyendo hasta $5 \%$ en el tercer año.

- Promedio de sanciones administrativas por incumplimiento de ley equivalente al monto máximo de una sanción grave equivalente a 50 UIT's. 


\section{Capítulo 7: Gestión del Proyecto}

En este capítulo se detallan las gestiones realizadas en torno a lo planificado al inicio del proyecto. Se presenta un estimado del tiempo de desarrollo de los entregables y el cronograma de actividades realizadas, las funciones realizadas por los miembros del proyecto y como se manejaron los riesgos presentados durante el transcurso del mismo. 


\section{Gestión del cronograma}

Las actividades se realizaron completamente y fueron divididas para el ciclo actual en inicio, planificación ejecución y cierre. En inicio se considera como entregable final al Project Charter, el cual tuvo un cambio luego de la presentación parcial, siendo los más resaltantes la delimitación del sector objetivo a micro financieras y la corrección de los objetivos. En la fase de planificación se considera la elaboración de documentos de gestión basados en PMI. En la fase de ejecución se encuentra el desarrollo de los capítulos de la memoria, el análisis del estado del arte, el diseño del modelo de madurez, la validación del modelo y el plan de continuidad del proyecto.

Tabla 15: Cronograma del proyecto

\begin{tabular}{|c|c|c|c|}
\hline EDT & Nombre de tarea & Comienzo & Fin \\
\hline 1 & Inicio del Proyecto & 31/03/17 & 18/04/17 \\
\hline 1.1 & $\begin{array}{l}\text { Elaboración del } \\
\text { Project Charter v0.1 }\end{array}$ & $31 / 03 / 17$ & $4 / 04 / 17$ \\
\hline 1.2 & $\begin{array}{l}\text { Hito: Presentación de } \\
\text { Project Charter v0.1 }\end{array}$ & $31 / 03 / 17$ & $31 / 03 / 17$ \\
\hline 1.3 & $\begin{array}{l}\text { Elaboración del } \\
\text { Project Charter v1.0 }\end{array}$ & $1 / 04 / 17$ & 18/04/17 \\
\hline 1.4 & $\begin{array}{l}\text { Hito: Presentación de } \\
\text { Project Charter v1.0 }\end{array}$ & $18 / 04 / 17$ & $18 / 04 / 17$ \\
\hline 2 & $\begin{array}{l}\text { Planificación del } \\
\text { Proyecto }\end{array}$ & $16 / 05 / 17$ & 20/05/17 \\
\hline 2.1 & $\begin{array}{l}\text { Elaboración de } \\
\text { Documentos de } \\
\text { Gestión }\end{array}$ & $16 / 05 / 17$ & $20 / 05 / 17$ \\
\hline 3 & $\begin{array}{l}\text { Ejecución del } \\
\text { Proyecto }\end{array}$ & 21/04/17 & 03/11/2017 \\
\hline 3.1 & $\begin{array}{l}\text { Presentación de } \\
\text { entregables y rúbricas }\end{array}$ & $21 / 04 / 17$ & 21/04/17 \\
\hline 3.2 & Exposición a Gerente & $25 / 04 / 17$ & $25 / 04 / 17$ \\
\hline 3.3 & $\begin{array}{l}\text { Exposición parcial al } \\
\text { Comité }\end{array}$ & $2 / 05 / 17$ & $2 / 05 / 17$ \\
\hline
\end{tabular}




\begin{tabular}{|c|c|c|c|}
\hline 3.4 & $\begin{array}{l}\text { Elaboración del } \\
\text { capítulo } 1 \text { de la } \\
\text { memoria }\end{array}$ & $2 / 05 / 17$ & $5 / 05 / 17$ \\
\hline 3.5 & $\begin{array}{l}\text { Aprobación del } \\
\text { capítulo } 1 \text { de la } \\
\text { memoria }\end{array}$ & $6 / 05 / 17$ & 6/05/17 \\
\hline 3.6 & $\begin{array}{l}\text { Elaboración del } \\
\text { capítulo } 3 \text { de la } \\
\text { memoria }\end{array}$ & $8 / 05 / 17$ & $19 / 05 / 17$ \\
\hline 3.7 & $\begin{array}{l}\text { Análisis del estado del } \\
\text { arte de los modelos de } \\
\text { madurez de } \\
\text { protección de datos y } \\
\text { Seguridad de } \\
\text { Información }\end{array}$ & $8 / 05 / 17$ & $19 / 05 / 17$ \\
\hline 3.8 & $\begin{array}{l}\text { Aprobación del } \\
\text { capítulo } 3 \text { de la } \\
\text { memoria }\end{array}$ & 20/05/17 & $20 / 05 / 17$ \\
\hline 3.9 & $\begin{array}{l}\text { Elaboración del } \\
\text { capítulo } 4 \text { de la } \\
\text { memoria }\end{array}$ & $21 / 05 / 17$ & $2 / 06 / 17$ \\
\hline 3.1 & $\begin{array}{l}\text { Aprobación del } \\
\text { capítulo } 4 \text { de la } \\
\text { memoria }\end{array}$ & $3 / 06 / 17$ & $3 / 06 / 17$ \\
\hline 3.11 & $\begin{array}{l}\text { Elaboración del } \\
\text { capítulo } 6 \text { de la } \\
\text { memoria }\end{array}$ & $5 / 06 / 17$ & $23 / 06 / 17$ \\
\hline 3.12 & \begin{tabular}{|l} 
Elaboración del \\
diseño del modelo de \\
madurez
\end{tabular} & $19 / 06 / 17$ & $23 / 06 / 17$ \\
\hline 3.13 & $\begin{array}{l}\text { Aprobación del } \\
\text { capítulo } 6 \text { de la } \\
\text { memoria }\end{array}$ & $24 / 06 / 17$ & $24 / 06 / 17$ \\
\hline 3.14 & $\begin{array}{l}\text { Aprobación del diseño } \\
\text { del modelo de } \\
\text { madurez }\end{array}$ & $3 / 07 / 17$ & $3 / 07 / 17$ \\
\hline 3.15 & $\begin{array}{l}\text { Presentación de } \\
\text { entregables y rúbricas }\end{array}$ & $4 / 07 / 17$ & $4 / 07 / 17$ \\
\hline
\end{tabular}




\begin{tabular}{|c|c|c|c|}
\hline 3.16 & $\begin{array}{l}\text { Aprobación del } \\
\text { capítulo } 1 \text { de la } \\
\text { memoria por cliente }\end{array}$ & $06 / 05 / 17$ & $06 / 05 / 17$ \\
\hline 3.17 & $\begin{array}{l}\text { Aprobación del } \\
\text { capítulo } 3 \text { de la } \\
\text { memoria }\end{array}$ & $20 / 05 / 17$ & $20 / 05 / 17$ \\
\hline 3.18 & $\begin{array}{l}\text { Aprobación del } \\
\text { capítulo } 4 \text { de la } \\
\text { memoria }\end{array}$ & 03/06/17 & $03 / 06 / 17$ \\
\hline 3.19 & $\begin{array}{l}\text { Aprobación del } \\
\text { capítulo } 6 \text { de la } \\
\text { memoria por cliente }\end{array}$ & $24 / 06 / 17$ & $24 / 06 / 17$ \\
\hline 3.2 & $\begin{array}{l}\text { Aprobación del } \\
\text { objetivo } 1 \text { del } \\
\text { proyecto por cliente }\end{array}$ & $31 / 06 / 17$ & $31 / 06 / 17$ \\
\hline 3.21 & $\begin{array}{l}\text { Aprobación del } \\
\text { objetivo } 2 \text { del } \\
\text { proyecto por cliente }\end{array}$ & $31 / 06 / 17$ & $31 / 06 / 17$ \\
\hline 3.22 & $\begin{array}{l}\text { Aprobación del } \\
\text { capítulo } 5 \text { por cliente }\end{array}$ & $12 / 09 / 17$ & $12 / 09 / 17$ \\
\hline 3.23 & $\begin{array}{l}\text { Aprobación del } \\
\text { objetivo } 3 \text { por cliente }\end{array}$ & $12 / 09 / 17$ & $12 / 09 / 17$ \\
\hline 3.24 & $\begin{array}{l}\text { Aprobación del } \\
\text { objetivo } 4 \text { por cliente }\end{array}$ & $27 / 10 / 17$ & $27 / 10 / 17$ \\
\hline 3.25 & $\begin{array}{l}\text { Aprobación del } \\
\text { capítulo } 2 \text { por cliente }\end{array}$ & $27 / 10 / 17$ & $27 / 10 / 17$ \\
\hline 3.26 & $\begin{array}{l}\text { Aprobación del } \\
\text { capítulo } 6 \text { por cliente }\end{array}$ & $03 / 11 / 17$ & $03 / 11 / 17$ \\
\hline 3.27 & $\begin{array}{l}\text { Aprobación del } \\
\text { capítulo } 7 \text { actualizado } \\
\text { por cliente }\end{array}$ & $03 / 11 / 17$ & $03 / 11 / 17$ \\
\hline 4 & Cierre del Proyecto & $14 / 10 / 17$ & 11/10/17 \\
\hline
\end{tabular}




\begin{tabular}{|c|l|c|c|}
4.1 & Exposición a Gerente & $14 / 10 / 17$ & $14 / 10 / 17$ \\
\hline 4.2 & $\begin{array}{l}\text { Exposición final al } \\
\text { comité }\end{array}$ & $21 / 10 / 17$ & $21 / 10 / 17$ \\
\hline
\end{tabular}

Fuente: Elaboración Propia

\section{Gestión de recursos humanos}

Las actividades designadas fueron cumplidas por los miembros del equipo de proyecto y se realizaron como se muestro en siguiente tabla:

Tabla 16: Resumen de actividades del proyecto

\begin{tabular}{|l|c|c|}
\hline \multicolumn{1}{|c|}{ Actividad } & $\begin{array}{c}\text { Jefe de } \\
\text { Proyecto }\end{array}$ & $\begin{array}{c}\text { Jefe de } \\
\text { Investigación }\end{array}$ \\
\hline Gestionar actividades del proyecto & $\mathrm{R}$ & $\mathrm{P}$ \\
\hline Coordinar reuniones con el profesor cliente & $\mathrm{P}$ & $\mathrm{R}$ \\
\hline Elaborar el Project Charter & $\mathrm{R} / \mathrm{P} / \mathrm{V}$ & $\mathrm{P}$ \\
\hline Elaborar documentos de gestión & $\mathrm{R} / \mathrm{P}$ & $\mathrm{R} / \mathrm{P} / \mathrm{V}$ \\
\hline Elaborar análisis de estado del arte & $\mathrm{P}$ & $\mathrm{R} / \mathrm{P}$ \\
\hline Elaborar capítulos 1 y 7 de la memoria & $\mathrm{R} / \mathrm{P}$ & $\mathrm{P} / \mathrm{V}$ \\
\hline Elaborar capítulos 3 y 4 de la memoria & $\mathrm{P} / \mathrm{V}$ & $\mathrm{R} / \mathrm{P}$ \\
\hline Elaborar diseño del modelo de madurez & $\mathrm{P} / \mathrm{V}$ & $\mathrm{R} / \mathrm{P}$ \\
\hline $\begin{array}{l}\text { Coordinar reuniones para la validación por } \\
\text { juicio de expertos }\end{array}$ & $\mathrm{P}$ & $\mathrm{R} / \mathrm{P}$ \\
\hline $\begin{array}{l}\text { Contactar con micro financieras para el caso } \\
\text { de estudio }\end{array}$ & $\mathrm{P}$ & $\mathrm{R} / \mathrm{P}$ \\
\hline Elaborar el capítulo 5 y 6 de la memoria & $\mathrm{R} / \mathrm{P}$ & $\mathrm{P} / \mathrm{V}$ \\
\hline Elaborar el capítulo 2 de la memoria & $\mathrm{V}$ & $\mathrm{R} / \mathrm{P}$ \\
\hline Elaborar el plan de continuidad del proyecto & $\mathrm{R} / \mathrm{P}$ & $\mathrm{P} / \mathrm{V}$ \\
\hline Actualizar repositorio del proyecto & $\mathrm{R}$ & $\mathrm{P}$ \\
\hline
\end{tabular}

R: Responsable, P: Participó, V: Validó

Fuente: Elaboración Propia 


\section{Gestión de riesgos}

Se establecieron los siguientes riesgos al inicio del proyecto, de los cuales, durante el transcurso del proyecto se presentaron aquellos resaltados en la tabla, para el riesgo $\mathrm{N}^{\circ} 2$ se acordó delimitar el alcance del proyecto, esto provocó hacer correcciones al Project Charter y replantear la búsqueda de fuentes. El riesgo $\mathrm{N}^{\circ} 3$ fue mitigado solicitando ampliación de la fecha de entrega para levantar las observaciones realizadas por el comité.

Tabla 17: Riesgos del proyecto

\begin{tabular}{|c|l|c|c|l|}
\hline$\#$ & Riesgo & Probabilidad & Impacto & \multicolumn{1}{|c|}{ Estrategia } \\
\hline 1 & $\begin{array}{l}\text { Retiro del algún } \\
\text { miembro del } \\
\text { proyecto }\end{array}$ & $10 \%$ & 5 & $\begin{array}{l}\text { Mitigar: Definición } \\
\text { del alcance del } \\
\text { proyecto }\end{array}$ \\
\hline 3 & $\begin{array}{l}\text { Cambio del alcance } \\
\text { del proyecto por } \\
\text { demanda del cliente }\end{array}$ & $50 \%$ & 4 & $\begin{array}{l}\text { Aceptar: Coordinar } \\
\text { cambio en el } \\
\text { alcance del } \\
\text { proyecto }\end{array}$ \\
\hline 4 & $\begin{array}{l}\text { Disconformidad por } \\
\text { parte del cliente o } \\
\text { gerente con respecto } \\
\text { a los entregables } \\
\text { presentados }\end{array}$ & $30 \%$ & 2 & $\begin{array}{l}\text { Mitigar: Establecer } \\
\text { punto medio o } \\
\text { solicitar ampliación } \\
\text { de la fecha de } \\
\text { entrega }\end{array}$ \\
\hline $\begin{array}{l}\text { Incumplimiento por } \\
\text { parte del equipo en } \\
\text { la entrega de } \\
\text { documentos } \\
\text { informativos }\end{array}$ & $30 \%$ & 2 & $\begin{array}{l}\text { Aceptar: Uso de } \\
\text { horas extras para } \\
\text { culminar los } \\
\text { documentos } \\
\text { pendientes }\end{array}$ \\
\hline 5 & $\begin{array}{l}\text { No se encuentre una } \\
\text { herramienta técnica } \\
\text { y económicamente } \\
\text { adecuada para la } \\
\text { implementación del } \\
\text { modelo de madurez }\end{array}$ & $50 \%$ & 3 & $\begin{array}{l}\text { Aceptar: Está } \\
\text { contemplado } \\
\text { desarrollar una } \\
\text { herramienta acorde } \\
\text { al modelo de } \\
\text { madurez diseñado }\end{array}$ \\
\hline
\end{tabular}

\section{Lecciones aprendidas}

Al finalizar los entregables realizados durante está parte del proyecto, se programa una reunión de los miembros del equipo para obtener información necesaria para mejorar el desempeño del proyecto para la siguiente fase del mismo. 
Fueron identificadas las siguientes lecciones aprendidas:

\section{Definir un límite de tiempo interno para la finalización de entregables}

Se identificó que había información incompleta o por corregir dentro de los entregables por lo que se considera necesario definir un tiempo de aprobación interna antes de presentarlo al profesor cliente o gerente.

\section{Necesidad de un repositorio de información interno}

Para el desarrollo de los documentos fue necesario utilizar una plataforma de almacenamiento online para control interno, los documentos aprobados de manera interna son trasladados a la carpeta compartida por el profesor gerente.

\section{Elaborar documentos de control interno}

Debido a la cantidad de entregables a realizar durante el proyecto, se consideró llevar un control de los mismos para cumplir con los tiempos de entrega. Cabe mencionar que este control también fue aplicado a la recolección de fuentes académicas. 


\section{Conclusiones}

- El resultado de este trabajo brinda una solución para el sector micro financiero que permita mejorar el nivel de protección de datos personales de sus organizaciones, sin que estas deban gastar grandes sumas de dinero en contratar los servicios de consultoras de seguridad de información.

- Al analizar los resultados del juicio de expertos, se concluye que el uso de la herramienta del modelo de madurez, teniendo una aprobación de 93\%, es intuitiva para el usuario final, permitiendo su sencillo manejo.

- Tras el juicio de expertos, el uso del modelo de madurez permite a las micro financieras una autoevaluación eficiente y que en base a estos resultados busquen escalar en los niveles del modelo, mejorando sus capacidades de protección de datos personales y generando una cultura de seguridad de información.

- Los resultados entregados por las micro financieras muestran la diferencias que existe entre las empresas con mayor poder económico, siendo las cooperativas las que se encuentran en un nivel más bajo con un promedio de $34 \%$ de cumplimiento, mientras que Mi Banco llega al 74\% de cumplimiento. 


\section{Recomendaciones}

Las recomendaciones que se han obtenido del proyecto son:

- La evaluación del modelo de madurez debe ser dado, por recomendación, por el oficial de Seguridad de Información, o en su defecto por un encargado del área de Seguridad de Información, Control Interno o Auditoría.

- Se recomienda hacer seguimiento a las modificaciones de la ley 29733, para ser incluidos en una nueva versión del modelo de madurez.

- Sería de beneficio para el modelo, migrar la herramienta a una plataforma web con la finalidad de que las entidades que la hayan utilizado previamente puedan hacer un seguimiento a la mejora de su nivel. 


\section{Glosario}

CEO: Gerente general, del inglés Chief Executive Office

CMAC: Caja Municipal de Ahorro y Crédito

CMMI: Del inglés Capacity Maturity Model Integration

COBIT: Objetivos de Control para Información y Tecnologías Relacionadas, del inglés

Control Objectives for Information and related Technology

PYME: Pequeña y media empresa

IEC: Comisión Electrotécnica Internacional del inglés International Electrotechnical Comission

LPDP: Ley de protección de datos personales

ISO: Organización Internacional de Normalización del inglés International Organization for Standarization

PCI DSS: Estándar de seguridad de datos para la industria de tarjetas de pago, del inglés Payment Card Industry Data Security Standard

PIN: Número de Identificación Personal, del inglés Personal Identification Number

PWC: Price Waterhouse Cooper

SBS: Superintendencia de Banca y Seguros

SME: Del inglés Small and Medium Enterprises 


\section{Bibliografía}

Alineamiento a la Ley de Protección de Datos Personales para MYPES/PYMES Tecnologías y Consultoría: http:/www.gtdi.pe/alineado-lpdp-mypes [Revisado el 30 mar. 2017]

Definición de Pyme: https://definicion.de/pyme/ [Revisado el 30 mar. 2017]

DELOITTE Ley de Protección de Datos Personales https://www2.deloitte.com/pe/es/pages/risk/articles/data_law_protection.html [Revisado el 30 mar. 2017]

Gestión http:/gestion.pe/economia/ley-proteccion-datos-personales-empresas-tienen-plazohasta-mayo-alinear-politica-seguridad-2125467 [Revisado el 1 abr. 2017]

Gestión http://gestion.pe/economia/cuatro-cada-cinco-pymes-son-informales-suficientereducir-igv-2168667 [Revisado el 1 abr. 2017]

$41 \%$ of mid-size EU businesses at risk of breaching incoming data privacy laws http://www.ironmountain.co.uk/About-Us/Company-News/News-Categories/Press-

Releases/2016/June/21.aspx [Revisado el 19 abr. 2017]

Entrevista al CEO de Ernst \& Young, Paulo Pantigoso http:/gestion.pe/tendencias/hayalgunos-servicios-consultoria-que-son-mas-sexis-que-otros-2101176 [Revisado el 19 abr. 2017] La informalidad y las unidades de producción https://www.inei.gob.pe/media/MenuRecursivo/publicaciones_digitales/Est/Lib1154/cap05.p df [Revisado el 19 abr. 2017]

Proenca, Diogo y otros (2016). A maturity model for information governance en nformation Systems and Technologies.

Hui Na Chua y otros (2017). Compliance to Personal Data Protection Principles: A Study of How Organizations Frame Privacy Policy Notices en Telematics and Informatics.

Youn-Rai Park y otros (2014). Study on financial-sector information security level assessment and improvement anticipation model en Science and Engineering Research Support Society.

Rossouw de Bruin y Von Solms SH (2016). Modelling Cyber Security Governance Maturity en Institute of Electrical and Electronics Engineers Inc.

Gurses, Seda y Del Alamo Jose M. (2016). Privacy Engineering: Shaping an Emerging Field of Research and Practice en Institute of Electrical and Electronics Engineers Inc. 
Gurses, Seda (2014). Privacy and security: Can you engineer privacy? The challenges and potential approaches to applying privacy research in engineering practice en Association for Computing Machinery.

Yildirim, Ebru Yeniman y otros (2011). Factors influencing information security management in small- and medium-sized enterprises: A case study from Turkey en International Journal of Information Management.

Craddock, Emma y otros (2017). Nobody puts data in a corner? Why a new approach to categorising personal data is required for the obligation to inform en Computer Law and Security Review.

Chao Li y otros (2014). A theory of pricing private data en Association for Computing Machinery.

Foukia, Noria y otros (2016). PISCES: A framework for privacy by design in IoT en Institute of Electrical and Electronics Engineers Inc.

Fal O. M. (2014). Standardization in personal data protection en Cybernetics and Systems Analysis.

Mijnhardt, Frederik y otros (2016). Organizational characteristics influencing SME information security maturity en International Association for Computer Information Systems.

Beckers, Kristian y otros (2014). ISMS-CORAS: A structured method for establishing an ISO 27001 compliant information security management system en ACM Transactions on Database Systems.

Rigon, Evandro y otros (2014). A cyclical evaluation model of information security maturity Approach en Lectures Notes in Computer Science.

Aserkar, Rajiv (2017). Impact of personal data protection (PDP) regulations on operations workflow en Human Systems Management.

Harbinja, Edina (2017). Post-mortem privacy 2.0: theory, law, and technology en International Review of Law, Computers and Technology

Rodrigues, Rowena y otros (2016). The future of privacy certification in Europe: an exploration of options under article 42 of the GDPR en International Review of Law, Computers and Technology.

Hemphill, Thomas A. y Longstreet Phil (2016). Financial data breaches in the U.S. retail economy: Restoring confidence in information technology security standards en Technology in Society. 
Bjoern, Roeber y otros (2015). Personal data: how context shapes consumers' data sharing with organizations from various sectors en Electronic Markets.

Johnston, Steven R. (2015). The impact of privacy and data protection legislation on the sharing of intrusion detection information.

Da Veiga, Adele y Martins Nico (2015). Information security culture and information protection culture: A validated assessment instrument en Computer Law and Security Review.

Mikkonen, Tomi (2015). Perceptions of controllers on EU data protection reform: A Finnish perspective en Computer Law and Security Review.

Zhang, Kunbei y otros (2016). Thinking of data protection law's subject matter as a complex adaptive system: A heuristic display en Computer Law and Security Review.

Maryam Al-Awadi, y Renaud, Karen (2016). Information security management system implementation success factors en Advance Science Letters.

Senarathna, Ishan y otros (2016). Security and privacy concerns for Australian SMEs cloud adoption: Empirical study of metropolitan vs regional SMEs en Australasian Journal of Information Systems.

Burdon, Mark y otros (2016). The regulatory challenges of Australian information security practice en Computer Law and Security Review.

Van der Sloot B. (2015). Do privacy and data protection rules apply to legal persons, and should they? A proposal for a two-tiered system en Computer Law and Security Review 